\title{
Climate impact of supersonic air traffic: an approach to optimize a potential future supersonic fleet - results from the EU-project SCENIC
}

\author{
V. Grewe ${ }^{1}$, A. Stenke ${ }^{1}$, M. Ponater ${ }^{1}$, R. Sausen ${ }^{1}$, G. Pitari ${ }^{2}$, D. Iachetti ${ }^{2}$, H. Rogers ${ }^{3}$, O. Dessens ${ }^{3}$, J. Pyle ${ }^{3}$, \\ I.S.A. Isaksen ${ }^{4}$, L. Gulstad ${ }^{4}$, O.A. Søvde ${ }^{4}$, C. Marizy ${ }^{5}$, and E. Pascuillo \\ ${ }^{1}$ Deutsches Zentrum für Luft- und Raumfahrt, Institut für Physik der Atmosphäre, Oberpfaffenhofen, 82230 Wessling, \\ Germany \\ ${ }^{2}$ Dipartimento di Fisica, Universita' L'Aquila, Italy \\ ${ }^{3}$ Center of Atmospheric Science, Department of Chemistry, University of Cambridge, United Kingdom \\ ${ }^{4}$ Department of Geoscience, University of Oslo, Norway \\ ${ }^{5}$ AIRBUS, Toulouse, France \\ ${ }^{6}$ AIRBUS, Hamburg, Germany
}

Received: 5 April 2007 - Published in Atmos. Chem. Phys. Discuss.: 8 May 2007

Revised: 9 August 2007 - Accepted: 27 September 2007 - Published: 5 October 2007

\begin{abstract}
The demand for intercontinental transportation is increasing and people are requesting short travel times, which supersonic air transportation would enable. However, besides noise and sonic boom issues, which we are not referring to in this investigation, emissions from supersonic aircraft are known to alter the atmospheric composition, in particular the ozone layer, and hence affect climate significantly more than subsonic aircraft. Here, we suggest a metric to quantitatively assess different options for supersonic transport with regard to the potential destruction of the ozone layer and climate impacts. Options for fleet size, engine technology (nitrogen oxide emission level), cruising speed, range, and cruising altitude, are analyzed, based on SCENIC emission scenarios for 2050, which underlay the requirements to be as realistic as possible in terms of e.g., economic markets and profitable market penetration. This methodology is based on a number of atmosphere-chemistry and climate models to reduce model dependencies. The model results differ significantly in terms of the response to a replacement of subsonic aircraft by supersonic aircraft, e.g., concerning the ozone impact. However, model differences are smaller when comparing the different options for a supersonic fleet. Those uncertainties were taken into account to make sure that our findings are robust. The base case scenario, where supersonic aircraft get in service in 2015, a first fleet fully operational in 2025 and a second in 2050, leads in our simulations to a near surface temperature increase in
\end{abstract}

Correspondence to: V. Grewe

(volker.grewe@dlr.de)
2050 of around $7 \mathrm{mK}$ and with constant emissions afterwards to around $21 \mathrm{mK}$ in 2100 . The related total radiative forcing amounts to $22 \frac{\mathrm{mW}}{\mathrm{m}^{2}}$ in 2050, with an uncertainty between 9 and $29 \frac{\mathrm{mW}}{\mathrm{m}^{2}}$. A reduced supersonic cruise altitude or speed (from Mach 2 to Mach 1.6) reduces both, climate impact and ozone destruction, by around $40 \%$. An increase in the range of the supersonic aircraft leads to more emissions at lower latitudes since more routes to SE Asia are taken into account, which increases ozone depletion, but reduces climate impact compared to the base case.

\section{Introduction}

The reduction of cruising time on inter-continental flights has a potential for a profitable economic market, if the gain in time is large enough to compensate for additional costs. This can only be achieved by increasing the speed significantly compared to present day subsonic aircraft, which usually fly at Mach 0.78 to $0.85(830-900 \mathrm{~km} / \mathrm{h})$. Supersonic cruising speed in the range of Mach 1.6 to Mach 2.0 $(1700 \mathrm{~km} / \mathrm{h}-2100 \mathrm{~km} / \mathrm{h})$ has the potential to pass this breakeven-point. This implies cruising altitudes in the range of $\approx 14 \mathrm{~km}(45000 \mathrm{ft})$ to $\approx 20 \mathrm{~km}(65000 \mathrm{ft})$, so that those aircraft would fly deeply in the stratosphere, at least at mid and high latitudes.

Subsonic and supersonic aircraft emit a range of gases and particulate matter, like carbon dioxide $\left(\mathrm{CO}_{2}\right)$, water vapour $\left(\mathrm{H}_{2} \mathrm{O}\right)$, nitrogen oxides $\left(\mathrm{NO}_{\mathrm{x}}\right)$, and sulphate aerosols. Some

Published by Copernicus Publications on behalf of the European Geosciences Union. 
of those, like $\mathrm{NO}_{\mathrm{x}}$, significantly change the chemical composition of the atmosphere, producing or destroying ozone depending on the region of emission, while water vapour and aerosols trigger contrails. IPCC (1999) estimated the climate impact contributions of those agents. They found that the partial replacement of subsonic aircraft by supersonic aircraft may lead to a climate impact in 2050 (in terms of radiative forcing), which is by about 50\% higher than for the subsonic fleet. Recently, Sausen et al. (2005) presented an updated version for the subsonic case, based on the results of the EU funded project TRADEOFF. They summarized that the total radiative forcing $(\mathrm{RF})$ is smaller than previously estimated, because of a strongly reduced radiative forcing from lineshaped contrails compared to IPCC (1999). This is a consequence of crude assumptions on optical thickness, height, and background conditions (e.g. other clouds) in earlier estimates, which were refined recently. However, both IPCC (1999) and Sausen et al. (2005) pointed out that the radiative forcing of contrail-cirrus, which has not yet been included in the total RF because of a missing best estimate, may potentially be very large and may increase the total RF by up to a factor of two. For supersonic aircraft most RF contributions are different from those of subsonic aircraft (IPCC, 1999), since emitted species have longer residence times in the stratosphere and play therefore a different role in the climate response to the aircraft emissions. IPCC (1999) identified water vapour emissions as the major contributor to a change in the RF from supersonic transport. Ozone changes, unlike to the subsonic case, lead to a negative RF, since emissions of nitrogen oxides in the stratosphere are leading to an enhanced ozone destruction via the catalytic $\mathrm{NO}_{\mathrm{x}}$-ozone destruction cycle (Johnston, 1971; Crutzen, 1971), and the ozone production via $\mathrm{NO}_{2}$ photolysis is less important at higher altitudes.

The EU-project SCENIC ("Scenario of aircraft emissions and impact studies on atmosphere and climate") focused on the atmospheric impact of possible future fleets of supersonic aircraft. In this paper, we examine options for a future High Speed (supersonic) Commercial Transport (HSCT) fleet and compare those mixed (sub- and supersonic) scenarios with a subsonic only scenario by the means of a combination of two metrics: a climate change metric and an ozone destruction metric. The first HSCTs are assumed to be in service in 2015 , reaching the whole fleet size of approximately 500 aircraft in 2025 and a second generation comes into service in 2050. The transport demand, in terms of revenue passenger kilometres (RPK), is increasing. All scenarios include the assumption of a constant total number of transported passengers (RPKs) at a given time. The analysed options and uncertainties of the supersonic configurations are: the emission index of $\mathrm{NO}_{\mathrm{x}}$, fleet size, cruising speed, range, and cruising altitude.

The SCENIC emission database (Rogers et al., 2007 ${ }^{1}$ ),

\footnotetext{
${ }^{1}$ Rogers, H., Marizy, C., Pascuillo, E., Egelhofer, R., and Pyle,
}

produced by AIRBUS, differs significantly from previous emission datasets because of the applied methodology. Rogers et al. (2007) ${ }^{1}$ followed an approach, which is based on a detailed analysis of the potential market, including an analysis of the time savings, and a number of technical realizations. This implies that the options in reducing speed and reducing height are not identical, though similar. And it also implies that all scenarios are optimized in terms of economical viability, which means that they are as realistic as possible.

In order to assess the environmental impact of a mixed subsonic/supersonic fleet and to compare different options for such a fleet, a metric is needed, which enables the straightforward quantitative inter-comparison. Various approaches have been used and discussed with respect to perturbations, relevant for the total aircraft effect. The most prominent are the concepts of radiative forcing (e.g. IPCC, 1999, Sausen et al., 2005), global warming potential (GWP) (Johnson and Derwent, 1996; IPCC, 2001; Svensson et al., 2004) and near surface temperature change (Sausen and Schumann, 2000). The merits and drawbacks of the RF concept have been widely analysed (e.g. IPCC, 1995, 1999; Fuglestvedt et al., 2003; Stuber et al., 2005; Hansen et al., 2005).

Although the forcing components can be calculated and compared in terms of RF units, the corresponding impact on climate, i.e. temperature, may compare to a significantly different result, depending on the specific nature of individual agents. Carbon dioxide has a long atmospheric lifetime in the order of decades, implying that an emission taking place at a certain time affects climate for a long period and may give a larger impact on temperature than agents with a short duration, but larger radiative forcing, e.g. contrails. The concept of the GWP tries to take this effect into account. However, it may largely depend on the chosen time horizon, and is therefore an ambiguous metric. We add that some of the RF caveats transfer to the GWP, for which RF is a key input parameter. Finally, it is extremely problematic to define a GWP for "aircraft $\mathrm{NO}_{\mathrm{x}}$ ", because it would depend on the chemical background, emission height and season (IPCC, 1999). For those reasons, in the present paper we concentrate on the potential near surface temperature change related to a scenario. This has the advantage that the specific nature of individual climate agents is taken into account via their efficacy. The calculation of the temperature change is based on a linearized climate model (Sausen and Schumann, 2000), which hereafter will be called linear response model (LR) AirClim.

A more detailed description of the emission data set is given in Sect. 2. Section 3 describes the overall approach, including a description of the used model systems. In Sect. 4 we present the impact of the potential HSCT fleet on the different climate agents, which is a summary of a number of

J.: Design options for future European supersonic transport, Atmos. Chem. Physc. Discuss., in preparation, 2007. 
Table 1. Characterization of the SCENIC aircraft emission database. S4 denotes the subsonic fleet for 2050, S5 the base case mixed fleet for 2050, and $\mathrm{P}$ various perturbation scenarios. Abbreviations: $\mathrm{nm}=$ nautical miles $=1852 \mathrm{~km}$; Pax = passenger; Tot. $=$ Total fleet; Sup. $=$ Supersonic fleet; Comm. = commercial fleet)

\begin{tabular}{|c|c|c|c|c|c|c|c|c|c|c|c|c|c|}
\hline \multirow[t]{2}{*}{ Scenario } & \multirow[t]{2}{*}{$\begin{array}{l}\text { Number } \\
\text { of Air- } \\
\text { craft }\end{array}$} & \multirow[t]{2}{*}{$\begin{array}{l}\text { Speed } \\
\text { Mach }\end{array}$} & \multirow[t]{2}{*}{$\begin{array}{l}\text { Max. } \\
\text { range } \\
\mathrm{nm}\end{array}$} & \multirow[t]{2}{*}{$\begin{array}{l}\text { Cruise } \\
\text { altitude } \\
\text { kfts }\end{array}$} & \multicolumn{2}{|c|}{$\begin{array}{c}\text { Revenue } \\
\text { pass. km } \\
10^{11} \text { pax km }\end{array}$} & \multicolumn{2}{|c|}{$\begin{array}{c}\text { Fuel } \\
\text { consumption } \\
\text { Tg/year }\end{array}$} & \multicolumn{2}{|c|}{$\begin{array}{c}\mathrm{NO}_{\mathrm{x}} \\
\mathrm{Tg}\left(\mathrm{NO}_{2}\right) / \text { year }\end{array}$} & \multicolumn{2}{|c|}{$\begin{array}{c}\mathrm{EI}\left(\mathrm{NO}_{\mathrm{x}}\right) \\
\mathrm{g}\left(\mathrm{NO}_{2}\right) / \mathrm{kg}(\text { fuel })\end{array}$} & \multirow{2}{*}{$\begin{array}{l}\text { Distance } \\
10^{10} \mathrm{~km} \\
\text { Comm. }\end{array}$} \\
\hline & & & & & Tot. & Sup. & Tot. & Sup. & Tot. & Sup. & Tot. & Sup. & \\
\hline S4-Sub & 0 & - & - & - & 178.2 & 0 & 677 & 0 & 7.35 & 0 & 10.85 & - & 11.67 \\
\hline S5-Mixed & 501 & 2.0 & 5400 & $54-64$ & 178.4 & 7.3 & 721 & 60 & 7.45 & 0.27 & 10.33 & 4.60 & 11.84 \\
\hline P2-EINO & 501 & 2.0 & 5400 & 54-64 & 178.4 & 7.3 & 721 & 60 & 7.75 & 0.57 & 10.74 & 9.63 & 11.84 \\
\hline P3-Size & 972 & 2.0 & 5400 & $54-64$ & 178.7 & 14.1 & 762 & 115 & 7.54 & 0.53 & 9.90 & 4.62 & 12.01 \\
\hline P4-Speed & 544 & 1.6 & 6000 & $47-59$ & 178.4 & 6.9 & 703 & 41 & 7.40 & 0.22 & 10.53 & 5.42 & 11.76 \\
\hline P5-Range & 558 & 2.0 & 5900 & $53-65$ & 178.5 & 8.3 & 733 & 74 & 7.64 & 0.49 & 10.41 & 6.61 & 11.88 \\
\hline P6-Height & 561 & 1.6 & 5900 & $43-55$ & 178.4 & 6.9 & 702 & 40 & 7.40 & 0.22 & 10.55 & 5.62 & 11.76 \\
\hline
\end{tabular}

companion papers (Stenke et al., 2007a; Søvde et al., 2007; Pitari et al., $2007^{2}$ ) and is thought to serve as an input and basis for the climate change calculation (Sect. 5.3) via an estimate of radiative forcing (Sect. 5.1) and climate sensitivity (Sect. 5.2). This also implies that a detailed discussion of the individual effects, e.g. on water vapour, ozone, contrails, etc. is given elsewhere. In order to reduce model dependencies, 4 chemistry-atmosphere models were applied, which give a range of uncertainty. Among those, only the ULAQ-CCM is capable of simulating the effect of black carbon and sulphate aerosols, while only the ECHAM model is applied for estimates of contrail impacts. In Sect. 6 an optimization of a potential future supersonic fleet with respect to atmospheric perturbations is discussed. Section 7 briefly addresses uncertainties beyond those already included in the analysis. A summary is given in the last Section.

\section{Emissions}

A detailed discussion of the SCENIC emission database is given in Rogers et al. $(2007)^{1}$, here we focus on the main characteristics. Market forecasts for the 2050 world air traffic demand give the total number of passengers and the mass of freight that will be transported on each commercial route. The transportation is made either by a subsonic fleet composed of "representative" subsonic aircraft (scenario S4) or by a mixed fleet in which part of subsonic aircraft is replaced by one of five supersonic configurations designed by European aircraft industry (base-case scenario S5 and perturbation scenarios P2 to P6). Each HSCT aircraft is designed to transport 250 passengers.

\footnotetext{
${ }^{2}$ Pitari, G., Iachetti, D., Mancini, E., Montanaro, V., Marizy, C., Dessens, O., Rogers, H., Pyle, J., Grewe, V., Stenke, A., and Søvde, O.: Radiative forcing from particle emissions by future supersonic aircraft, Atmos. Chem. Physc. Discuss., in preparation, 2007.
}

Main characteristics of these scenarios are given in Table 1. A supersonic route network is defined for each scenario from characteristics of the selected aircraft (speed, cruise, range, mass, engine combustor technology-level) and its flight performances. Economic criteria are also considered like flight frequency, time saved or distance flown on these routes (cruise flights in supersonic mode being prohibited over land to avoid the sonic boom, modified trajectories are used to optimise the flight, which increases the distance flown on specific routes). Only routes are considered, where $20 \%$ time savings can be achieved by supersonic transport. For each route, a mean-level market penetration is defined to quantify the percentage of supersonic passengers and the number of supersonic aircraft needed to satisfy the demand. A maximum possible market penetration of $30 \%$ is assumed. A higher-level market penetration has also been used in scenario P3 (double fleet size) to evaluate the environmental impact of a more important demand for high-speed mean of transport. Optimised flight profiles integrating foreseen air traffic management improvements are used to calculate emissions produced by each aircraft on each route.

The main results, which are given in Table 1, underline the emission variations when varying supersonic parameters like engine technology $(\mathrm{P} 2)$, cruise speed ( $\mathrm{P} 4)$, maximal range (P5) and flight altitude (P6). The scenario P3 is included to test the sensitivity to the fleet size. As an example, the optimisation and boundary conditions (market penetration, time savings) for scenario P4 lead to fewer selected routes comnpared to S5 and hence it requires more aircraft to enhance the market penetration on other routes. The supersonic aircraft chosen for P4 is optimised in design to achieve a cruising speed of MACH 1.6 this also leads to lower cruising altitudes, however the design differs from that for P6, where the cruise altitude is chosen. As a consequence also the number of required aicraft differs. 
Table 2. Characterization of the global chemistry-atmosphere models applied to calculate chemical perturbations.

\begin{tabular}{|c|c|c|c|c|c|}
\hline $\begin{array}{l}\text { Model name } \\
\text { Type } \\
\text { Institution }\end{array}$ & $\begin{array}{l}\text { Resolution } \\
\text { (Lon. } \times \text { Lat.) } \\
\text { (bottom/top layer center) }\end{array}$ & $\begin{array}{l}\text { Tropospheric } \\
\text { Chemistry }\end{array}$ & $\begin{array}{l}\text { Stratospheric } \\
\text { Chemistry }\end{array}$ & $\begin{array}{l}\text { Coupling } \\
\text { Chem.- } \\
\text { Dyn. }\end{array}$ & Reference \\
\hline $\begin{array}{l}\text { E39/C } \\
\text { CCM } \\
\text { DLR-Oberpfaff. }\end{array}$ & $\begin{array}{l}\mathrm{T} 30\left(3.8^{\circ} \times 3.8^{\circ}\right) \\
39 \text { levels } \\
\text { sfc/10 } \mathrm{hPa}\end{array}$ & $\begin{array}{l}\text { Methane oxidation } \\
37 \text { species, } \\
12 \text { advected }\end{array}$ & $\begin{array}{l}\text { Cl-chemistry } \\
\text { incl. } \\
\text { PSC/aerosols }\end{array}$ & $\begin{array}{l}\mathrm{O}_{3}, \mathrm{CFCs}, \\
\mathrm{N}_{2} \mathrm{O}, \mathrm{CH}_{4}, \\
\text { Hydr. cycle }\end{array}$ & $\begin{array}{l}\text { Hein et al. }(2001) \\
\text { Stenke et al. }(2007 b)^{3}\end{array}$ \\
\hline $\begin{array}{l}\text { SLIMCAT } \\
\text { CTM } \\
\text { Univ. Cambridge }\end{array}$ & $\begin{array}{l}\mathrm{T} 15\left(7.5^{\circ} \times 7.5^{\circ}\right) \\
18 \text { isentropic levels } \\
200 \mathrm{hPa} / 0.3 \mathrm{hPa}\end{array}$ & $\begin{array}{l}\text { No troposph. } \\
\text { Chemistry }\end{array}$ & $\begin{array}{l}\mathrm{Cl} / \mathrm{Br} \text {-chem. } \\
\text { incl. PSC/aerosols } \\
33 \text { species, } 19 \text { advected }\end{array}$ & $\begin{array}{l}\text { ECMWF } \\
\text { Meteorology }\end{array}$ & $\begin{array}{l}\text { Chipperfield et al. (1996) } \\
\text { Chipperfield (1999) }\end{array}$ \\
\hline $\begin{array}{l}\text { OsloCTM2 } \\
\text { CTM } \\
\text { Univ. Oslo }\end{array}$ & $\begin{array}{l}\mathrm{T} 42\left(2.8^{\circ} \times 2.8^{\circ}\right) \\
40 \text { levels } \\
\mathrm{sfc} / 10 \mathrm{hPa}\end{array}$ & $\begin{array}{l}\text { NMHC, PAN } \\
58 \text { species }\end{array}$ & $\begin{array}{l}\mathrm{Cl} / \text { Br-chem. } \\
\text { incl. } \\
\text { PSC/aerosols }\end{array}$ & $\begin{array}{l}\text { ECMWF } \\
\text { Meteorology }\end{array}$ & Sundet (1997) \\
\hline $\begin{array}{l}\text { ULAQ } \\
\text { CCM } \\
\text { Univ. L'Aquila }\end{array}$ & $\begin{array}{l}22.5^{\circ} \times 10^{\circ} \\
26 \text { levels } \\
\text { sfc/0.04 hPa }\end{array}$ & $\begin{array}{l}\text { NMHC, PAN, } \\
\text { S-chemistry, } \\
\text { aerosols, } \\
40 \text { species, } \\
26 \text { advected }\end{array}$ & $\begin{array}{l}\mathrm{Cl} / \mathrm{Br} \text {-chem. } \\
\text { incl. PSC/aerosols }\end{array}$ & $\begin{array}{l}\mathrm{CO}_{2}, \mathrm{H}_{2} \mathrm{O}, \\
\mathrm{CH}_{4}, \mathrm{O}_{3}, \\
\mathrm{~N}_{2} \mathrm{O}, \mathrm{CFCs}, \\
\mathrm{HCFCs}, \\
\text { aerosols }\end{array}$ & Pitari et al. (2002a) \\
\hline
\end{tabular}

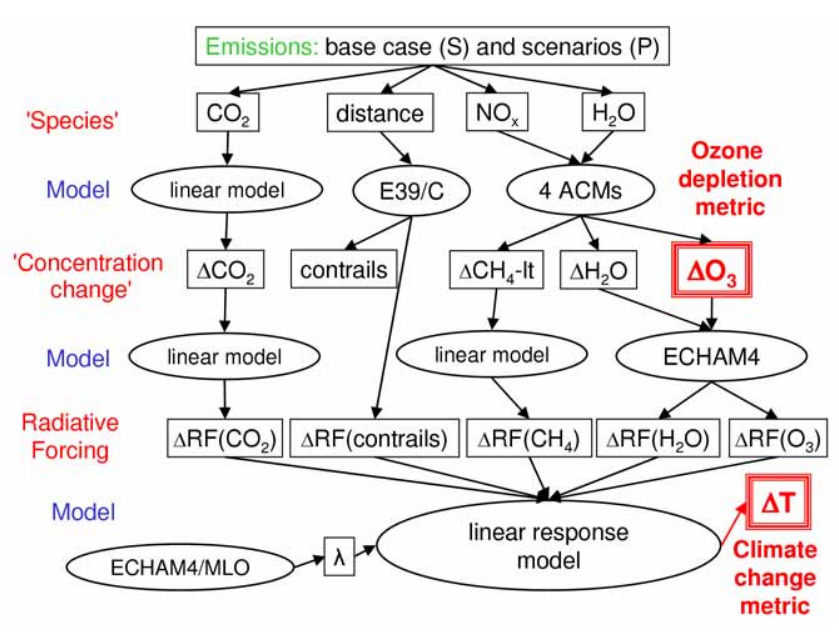

Fig. 1. Overview on the multi-step approach to derive near surface temperature changes and ozone depletion from emission scenarios.

\section{Methodology}

An overview on the applied multi-step procedure is given in Fig. 1. It first needs a time dependent (transient) emission scenario from which changes in the concentrations of various species are calculated, leading to an estimate of the adjusted radiative forcing of each individual species, or climate agents, and together with the innate climate sensitivity of that agent this directly relates to a time dependent temperature change by applying the LR AirClim.

\subsection{Transient $\mathrm{CO}_{2}$ emission and concentration scenarios}

To derive a temporal evolution of the subsonic aircraft $\mathrm{CO}_{2}$ emission, we start with a reference scenario of $0.15 \mathrm{GtC}$ in 1990 (taken from TRADEOFF, e.g. Sausen et al., 2005) and exponentially interpolate to $0.33 \mathrm{GtC}$ in 2025 and $0.58 \mathrm{GtC}$ in 2050 (S4; see also Rogers et al., $2007^{1}$ ). From that the perturbation scenarios are introduced in 2015 (first in service of HSCT) interpolated to 2025 and 2050 in a similar manner (Figs. 2a, d). Taking into account a turn around time of 50 years, the aircraft induced $\mathrm{CO}_{2}$ concentration for each scenario can be derived (Figs. $2 b$, e). Note, that this turn around time applies only for a perturbation of the background. The general lifetime of $\mathrm{CO}_{2}$ is significantly larger. In general, a simple linearized approach, applying a constant atmospheric decay time is insufficient to describe the $\mathrm{CO}_{2}$ concentrations (Sausen and Schumann, 2000; Fuglestvedt et al., 2003). However, in this case, we only look at small changes between two scenarios, which do not change the background concentration significantly and which therefore allow a linearized approach. The $\mathrm{CO}_{2}$ lifetime has been tuned such that the temporal development of $\mathrm{CO}_{2}$ concentrations fits with results presented in IPCC (1999), applying the same $\mathrm{CO}_{2}$ emissions for the period 1990 to 2050. The approach differs from that of a fixed atmospheric fraction, which assumes a certain percentage to remain in the atmosphere. In our approach, the time profile of the emissions is regarded, which leads to higher fractions of more recent emissions. Emissions remain constant after 2050 for all scenarios. 
a

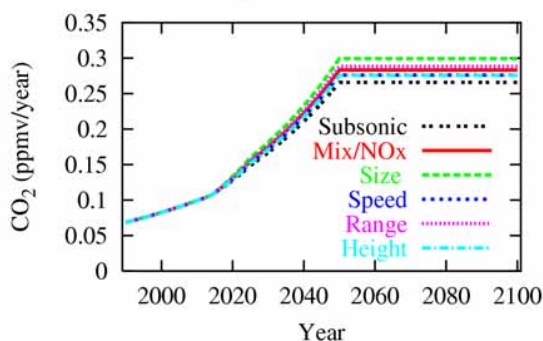

d

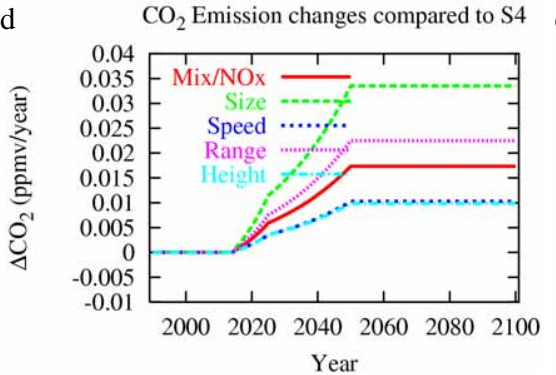

b

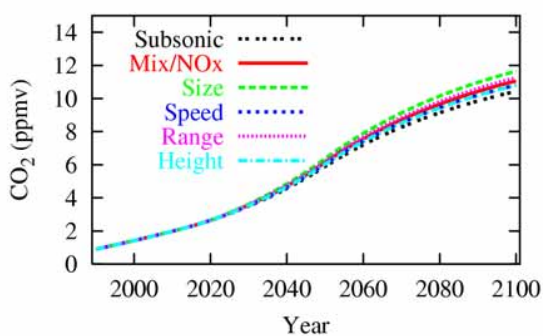

$\mathrm{CO}_{2}$ Concentration changes compared to $\mathrm{S} 4 \mathrm{f}$

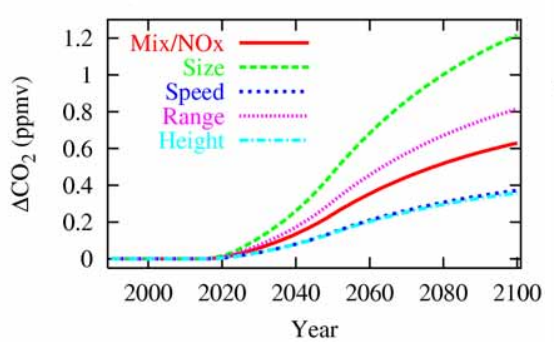

c

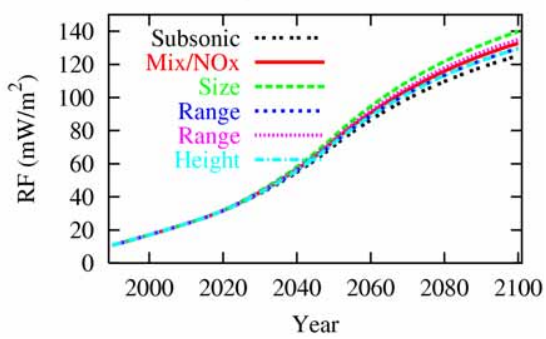

$\mathrm{CO}_{2}$ Radiative Forcing changes compared to $\mathrm{S} 4$

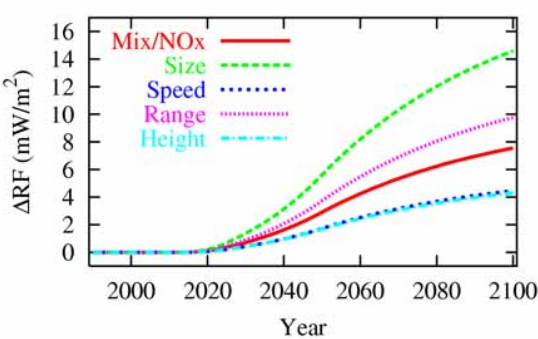

Fig. 2. Temporal development of aircraft $\mathrm{CO}_{2}$ emissions (ppmv/year) for the scenarios S4 (Subsonic), S5 (Mixed), P2 (NOx), P3 (Size), P4 (Speed), P5 (Range) and P6 (Height), as totals (a) and subsonic aircraft emissions subtracted (d). Respective simulated volume mixing ratio of $\mathrm{CO}_{2}$ (ppmv) (b) and subsonic scenario (S4-subsonic) subtracted (e). And respective $\mathrm{RF}\left(\frac{\mathrm{mW}}{\mathrm{m}^{2}}\right)$ for the totals (c) and the subsonic scenario subtracted (f). In terms of $\mathrm{CO}_{2}$, the scenarios S5-Mixed (red) and P2-NOx (red) are identical. The scenarios P4-Speed (dark blue) and P6-Height (light blue) are very close and may not be distinguished on all figures.

3.2 Calculation of changes in concentration of $\mathrm{O}_{3}, \mathrm{H}_{2} \mathrm{O}$, $\mathrm{CH}_{4}$, and contrail occurrence

Emissions of supersonic aircraft mainly perturb the radiative active gases water vapour, ozone, $\mathrm{CO}_{2}$, methane, and lead to changes in cloudiness (contrails). The concentration changes of water vapour and ozone are calculated using a set of threedimensional global chemistry atmosphere models ( 2 chemical transport models, CTMs and 2 chemistry-climate models, CCMs). A brief description of the models is given in Table 2. The two models SLIMCAT and Oslo-CTM2 use the same meteorological data and the same advection scheme (Prather, 1986) and E39/C a Lagrangian advection scheme (Stenke et al., $2007 \mathrm{~b}^{3}$ ). Multi-annual steady state simulations are performed for the time-slice 2050 (CTMs apply meteorological input fields for 1990 to 1999), excluding a spin-up time to take into account accumulation effects. Since the simulations are quite resource demanding, only the scenarios $\mathrm{S} 4, \mathrm{~S} 5$, and P4 were simulated by all models (see also Fig. 8).

From these simulations the tropospheric $\mathrm{OH}$ change is derived to calculate changes in the tropospheric methane lifetime. Changes in the $\mathrm{OH}$ concentration of the lower troposphere are underestimated due to the fixed boundary condition of methane. Therefore, an additionally off-set factor of

\footnotetext{
${ }^{3}$ Stenke, A., Grewe, V., and Ponater, M.: Lagrangian transport of water vapor and cloud water in the ECHAM4 GCM and its impact on the cold bias, J. Climate, revised, 2007b.
}

1.4 is applied to the methane lifetime change (IPCC, 1999). A fixed boundary is chosen to reach steady state in a reasonable time, since the lifetime of methane of roughly 9 years would require simulation lengths of 15 years. The lifetime changes then directly correspond to a change in the concentration.

These steady-state simulations result in the calculation of a concentration change of species $i$ for the time around 2050, from which a temporal development of the mean stratospheric concentration change can be calculated, using a linearized approach:

$\frac{d \Delta C_{i}(t)}{d t}=\Delta E_{i}(t)-\tau_{i}^{-1} \times \Delta C_{i}(t)$,

where $\Delta C_{i}(t)$ is the perturbation of a concentration and $\Delta E_{i}(t)$ the perturbation of emissions of species $i$ with respect to the base case scenario (subsonic case) at time $t_{0}=1990$. The stratospheric turn around-time for water vapour $\left(\tau_{\mathrm{H}_{2} \mathrm{O}}\right)$ and $\mathrm{NO}_{\mathrm{y}}\left(\tau_{\mathrm{NO}_{\mathrm{y}}}\right)$ perturbations are by nature very close, since for both the main loss is the stratosphereto-troposphere exchange. They can be determined from the steady state simulations:

$\tau_{\mathrm{H}_{2} \mathrm{O}}=\tau_{\mathrm{NO}_{\mathrm{y}}}=\tau=\frac{\Delta C_{i}(t=2050)}{\Delta E_{i}(t=2050)}$

For line-shaped contrails the coverage is estimated using the CCM E39/C, which includes a parameterization of contrails (Ponater et al., 2002), based on the Schmidt-Appleman 
theory (Schmidt, 1941; Appleman, 1953). Contrails are handled as an individual cloud type and can occur simultaneously with natural cirrus. Optical properties (effective radii, emissivity and optical depth) are calculated using the equivalent relations as for natural cirrus. The lifetime is assumed to be 30 minutes, i.e. one model time step. It has been shown that this methodology is able to realistically reproduce global patterns of contrail coverage and also seasonal and diurnal cycles (Marquart et al., 2003; Meyer et al., 2007). This scheme has also been used to estimate the impact of flight altitude changes of a conventional subsonic fleet on contrail coverage and RF (Fichter et al., 2005).

\subsection{Radiative forcing}

Based on the simulated changes in the concentration of the various species the change in radiative forcing is calculated. For water vapour and ozone, multi-annual monthly mean three-dimensional change patterns are derived from CTM and CCM output. These changes are then introduced into the climate model E39 (Land et al., 1999) for a dedicated calculation of the stratosphere adjusted radiative forcing (for technical details see Stuber et al., 2001). A three months spin-up is taken into account for adjustment of the stratosphere and a one year simulation is evaluated.

For $\mathrm{CO}_{2}$, a more simple methodology is applicable, because the changes of the concentration are small compared to the background and, more important, $\mathrm{CO}_{2}$ is a well-mixed greenhouse gas and the radiative forcing is independent from the place of emission. The differential radiative forcing is estimated to decrease from 1990 to 2050 from $18 \frac{\mathrm{mW}}{\mathrm{m}^{2} \mathrm{ppmv}}$ to $12 \frac{\mathrm{mW}}{\mathrm{m}^{2} \mathrm{ppmv}}$ (IPCC, 1999). For methane, the calculated change in its tropospheric lifetime directly relates to the change in the concentration and in the radiative forcing. As a reference $470 \frac{\mathrm{mW}}{\mathrm{m}^{2}}$ are taken into account for 1990 .

The radiative forcing of contrails, for which the cooccurrence with natural clouds is essential, is calculated online during CCM simulation according to the method of Stuber et al. (2001). Following the outcome of the validation study by Marquart and Mayer (2002), the global longwave $\mathrm{RF}$ is posteriori enhanced by an offset of $25 \%$ to reach best estimates of the net RF that account for the neglect of longwave scattering in the CCM's radiation scheme.

\subsection{Climate change and climate sensitivity}

From the radiative forcing the change in the global mean near surface temperature can be approximated based on the relationship:

$\Delta T^{\mathrm{eq}}=\lambda \times R F$,

where $\Delta T^{\text {eq }}$ denotes the equilibrium change in near surface temperature, $\lambda$ the climate sensitivity parameter and RF is the radiative forcing related to a change in either a greenhouse gas concentration or contrails. It has been common to assume (e.g., IPCC, 1995) that this relationship is valid with constant $\lambda$ for all forcing agents from experience gained with model experiments using changes of well-mixed greenhouse gases or solar constant changes (Manabe and Wetherald, 1975; Wetherald and Manabe, 1975). However, aircraft related climate perturbations are basically non-homogeneous. Here we take into account more recent results which indicate that the differential efficacy of such perturbations requires the use of individual climate sensitivity parameters $\lambda_{i}$ (Hansen et al., 1997, 2005; Joshi et al., 2003; Ponater et al., 2005).

The values of $\lambda_{i}$ have to be determined by applying the atmosphere-ocean model E39/MLO in multi-decadal simulations (Ponater et al., 2005, 2006), generally using stronger perturbations than those produced by aircraft. For our study we refer to simulations with either idealized perturbations, e.g., in the upper troposphere, or northern hemisphere only, or to more realistic simulations, i.e., for ozone changes from subsonic aircraft. We also recall that beyond its dependency on the nature of the forcing agent, $\lambda_{i}$ also displays a distinct model dependency (Cess et al., 1989; IPCC, 2001), while the efficacy $\lambda_{i} / \lambda_{\mathrm{CO}_{2}}$ is much less variable among different models (Joshi et al., 2003).

As mentioned above we will use $\Delta T$ as a metric of climate change in this paper and apply the methodology described in Sausen and Schumann (2000), extended by the introduction of individual efficacy values into their equation (8). The basic relations are thus:

$$
\Delta T(t)=\int_{t_{0}}^{t} G_{T}\left(t-t^{\prime}\right) \times R F^{*}\left(t^{\prime}\right) d t^{\prime}, \text { with }
$$

$$
\begin{aligned}
G_{T}\left(t-t^{\prime}\right)= & \alpha_{T} \times e^{-\frac{t-t^{\prime}}{\tau_{T}}}, \\
& \text { with } \alpha_{T}=2.246 / 36.8 \frac{K}{y r} \\
& \text { and } \tau_{T}=36.8 \mathrm{yr}, \\
R F^{*}(t)= & \sum_{\text {all species } i} \frac{R F_{i}^{2050}}{R F_{\mathrm{CO}_{2}}^{2050}} \times \frac{\lambda_{i}}{\lambda \mathrm{CO}_{2}} \times \frac{\Delta C_{i}(t)}{\Delta C_{i}(2050)} .
\end{aligned}
$$

$\Delta T$ describes the perturbation temperature with respect to the base case, $G_{T}$ the Green's function for the near surface temperature response and $R F^{*}$ the normalized radiative forcing. Because of the small changes in the concentration, especially for $\mathrm{CO}_{2}$, saturation effects are omitted, different to the approach by Sausen and Schumann (2000). $R F_{\mathrm{CO}_{2}}^{2050}$ and $\lambda \mathrm{CO}_{2}$ are specific values for $\mathrm{CO}_{2}$, whereas $R F_{i}^{2050}$ and $\lambda_{i}$ are different for the respective climate agents (water vapour, ozone, methane, contrails). Except for the contrail case $\Delta C_{i}(t)$ represents the concentration perturbation of agent $i$, while for contrails the fuel consumption perturbation is used to describe the temporal change. 
Table 3. Characterization of the simulated annual mean equilibrium response of water vapour emissions for the scenario S5 minus S4. The last column gives the relative change of the perturbation in the lower speed scenario P4, i.e. P4-S4, with respect to S5-S4.

\begin{tabular}{lcccccc}
\hline Water vapour & E39/C & OsloCTM2 & ULAQ & SLIMCAT & Mean & P4 \\
\hline Perturbation [Tg] & 56 & 59 & 45 & 98 & 64 & $-38 \%$ \\
Life time [months] & 17 & 18 & 13 & 29 & 19 & $-10 \%$ \\
Hemispheric & 3.23 & 4.20 & 2.60 & 1.80 & 2.96 & $+5 \%$ \\
contrast [frac.] & & & & & & \\
\hline
\end{tabular}

\section{Impact of HSCT emissions on atmospheric composi- tion}

In order to estimate the climate impact resulting from a partial substitution of subsonic aircraft by supersonic aircraft, we follow the methodology described in Sects. 3.1 and 3.2 (see also Fig. 1). We first discuss the calculated concentration changes. The next section will then concentrate on the consequences for RF and temperature changes based on these concentration changes.

\subsection{Carbon dioxide}

Figure 2 shows the development of the global emissions (a, d) and resulting concentration (b, e) of $\mathrm{CO}_{2}$ for the individual scenarios and the change due to the replacement by supersonic aircraft, respectively. Clearly, the long atmospheric lifetime of $\mathrm{CO}_{2}$ prevents a convergence of the $\mathrm{CO}_{2}$ concentration towards equilibrium even 50 years after the emissions are kept constant. In the year 2100 , the concentration of HSCT emitted $\mathrm{CO}_{2}$ is doubled for a doubled fleet (P3), and about $45 \%$ reduced in the cases of a lower speed (P4) and lower flight altitude (P6). An increase in the $\mathrm{CO}_{2}$ concentration of $30 \%$ to $35 \%$ is found for the long range flights (P5) compared to the standard mixed fleet (S5).

\subsection{Water vapour}

Figure 3 shows the simulated equilibrium perturbations (i.e. mixed fleet "S5" minus subsonic only "S4") for water vapour. Since the response is relatively large (order of 5$10 \%$ ), the difference is based on a multi-annual mean, and the meteorology of all simulations is identical, the changes are highly statistical significant. Maximum perturbations occur at similar regions in all models, with different absolute values, though. Table 3 gives a characterization of the perturbation pattern in the various models. The total stratospheric mass of water vapour, which results from HSCT emissions ranges between 45 and $98 \mathrm{Tg}$, which is a factor of two. The lifetime of the water vapour perturbation (Eq. 2) ranges from 13 to 29 months. Those numbers must not be mixed up with the stratospheric age of air (Hall and Plumb, 1994) which reflects the mean lifetime of an air parcel entering the stratosphere in the tropics. The HSCT emissions are located much
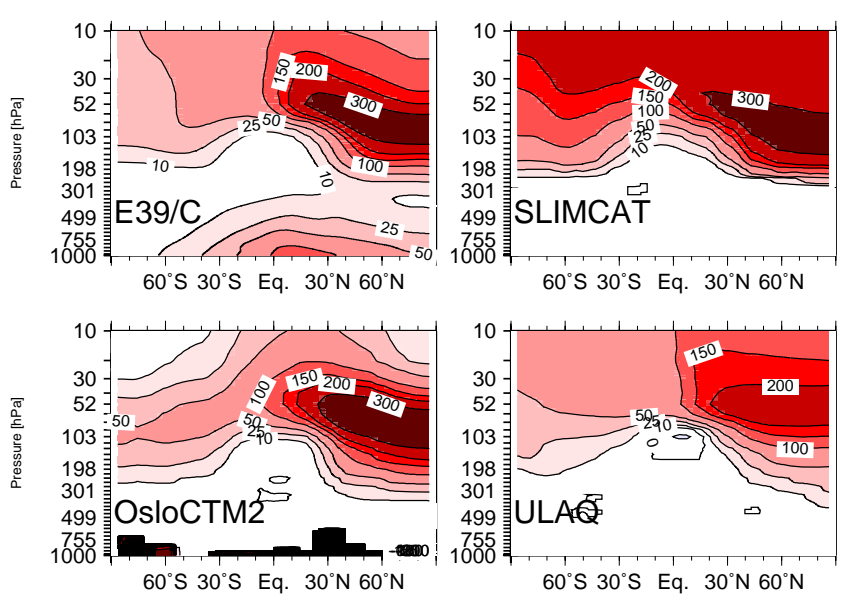

Fig. 3. Simulated annual mean water vapour change (ppbv) caused by a partial substitution of sub- by supersonic aircraft (S5 minus S4) for the time-slice 2050, derived with the models E39/C, SLIMCAT, OsloCTM2 and ULAQ.

closer to regions of strong exchange into the troposphere (e.g. Holton et al., 1995) so that the lifetime has to be smaller than the stratospheric age of air.

The inter-hemispheric ratio of the water vapour perturbation, i.e. the ratio of the northern hemisphere to southern hemisphere water vapour increase, is most pronounced in the OsloCTM2 model and the less in the SLIMCAT model. That implies that the tropics are a stronger barrier to transport in the OsloCTM2 model than in the SLIMCAT model. This may partly arise from the lower upper boundary condition in the OsloCTM2 model, which may inhibit long-range transport in the middle-world.

The pattern of the perturbation is very similar in all other scenarios (not shown), except for a shift in altitude of the maximum water vapour perturbation P4 (lower speed) and P6 (lower flight altitude). This implies a reduction of the total water vapour perturbation ranging between 19\% (SLIMCAT) and $57 \%$ (ULAQ), with a mean value of about $-40 \%$ (Table 3). This reduction is a consequence of two factors: a reduced HSCT fuel consumption (33\%, Table 1) and a reduced lifetime of the perturbation $(-10 \%$, Table 3$)$, caused 
Table 4. Characterization of the simulated annual mean equilibrium response of ozone for the scenario S5 minus S4. The last column gives the relative change of the perturbation in the lower speed scenario P4, i.e. P4-S4, with respect to S5-S4.

\begin{tabular}{lcccccc}
\hline Ozone & E39/C & OsloCTM2 & ULAQ & SLIMCAT & Mean & P4 \\
\hline Perturbation [Tg] & -7 & -11 & -1 & -16 & -8 & $+65 \%$ \\
$\begin{array}{l}\text { Hemispheric contrast } \\
\text { in } \mathrm{O}_{3} \text {-Loss [frac.] }\end{array}$ & 1.71 & 2.48 & 1.52 & 1.57 & 1.70 & $+12 \%$ \\
\hline
\end{tabular}

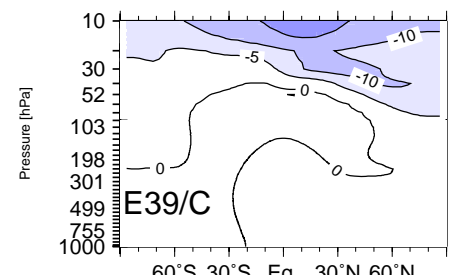

$60^{\circ} \mathrm{S} 30^{\circ} \mathrm{S}$ Eq. $30^{\circ} \mathrm{N} 60^{\circ} \mathrm{N}$
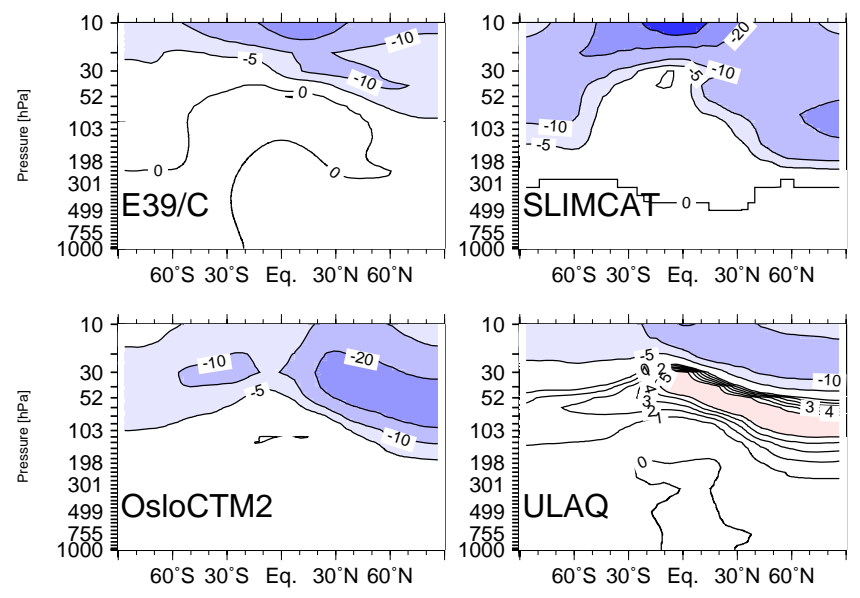

Fig. 4. As Fig. 3, but for ozone.

by the lower emission height. The water vapour perturbation has a smaller chance to be transported into the Southern Hemisphere, because the emission height is reduced, which increases the inter-hemispheric contrast by $7 \%$, with a model range of $0.5 \%$ (SLIMCAT) to $11 \%$ (E39/C, ULAQ).

\subsection{Ozone}

The statistical significant equilibrium response of ozone caused by $\mathrm{NO}_{\mathrm{x}}$ and $\mathrm{H}_{2} \mathrm{O}$ HSCT emissions is shown in Fig. 4 . An ozone decrease is found in all models, which is located at higher altitudes in the tropics compared to extra-tropical regions. This reflects the Brewer-Dobson circulation with its rising branch in the tropics and subsidence at higher latitudes. The ozone increase found in some models at lower altitudes is a superposition of various processes. The turnover point from ozone production (troposphere) to ozone loss (mid stratosphere) for an additional $\mathrm{NO}_{\mathrm{x}}$ emission is simulated differently by the models. Additionally, the vertical transport of airmasses with nitrogen oxides enhanced concentrations and ozone reduced concentrations from the mid stratosphere to the lower stratosphere and troposphere is also simulated differently. The E39/C and ULAQ models have the lowest ozone depletion induced by a replacement of subsonic by supersonics aircraft. The downward transport of these ozone reduced airmasses compensates for the $\mathrm{NO}_{\mathrm{x}}$ in-

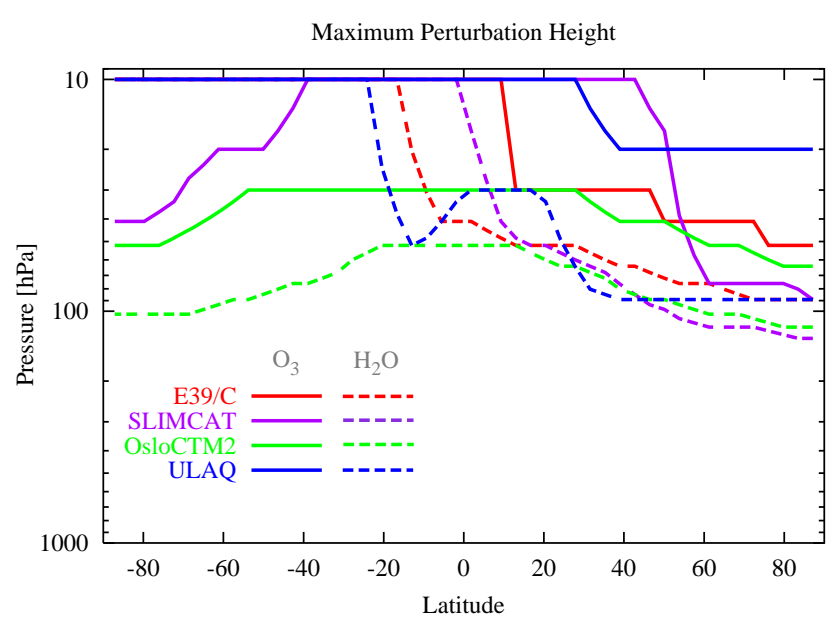

Fig. 5. Height of the maximum perturbation of water vapour (dashed) and ozone (solid) for the 4 models E39/C (red), SLIMCAT (magenta), OsloCTM2 (green) and ULAQ (blue). E39/C shows maximum perturbation at $10 \mathrm{hPa}$, shown is a secondary maximum at lower altitude.

duced ozone production in the lower stratosphere. Therefore, this compensation is weaker in E39/C and ULAQ compared to SLIMCAT and OsloCTM2, which leads to local ozone increase in the lower stratosphere only in E39/C and ULAQ models. The absolute ozone losses differ remarkably (Table 4) ranging from 1 to $16 \mathrm{Tg}$.

The patterns also differ in terms of inter-hemispheric differences. All models show larger ozone losses on the northern hemisphere than on the southern hemisphere (mean $\mathrm{NH}$ to SH perturbation ratio: 1.7 ). The OsloCTM2 model shows ozone changes, which are more confined to the northern hemisphere than in the other models (ratio: 2.5, Table 4), which is in agreement with results for water vapour.

Figure 5 compares the altitude of the maximum perturbation in water vapour (dashed line) and the maximum ozone loss (solid line) for the four models. Clearly, the Northern Hemisphere maximum water vapour perturbation is located at similar heights in all models, indicating a maximum perturbation near the HSCT emission region. However, the transport to the Southern Hemisphere is very differently simulated, leading to maximum changes between 10 and $50 \mathrm{hPa}$. 

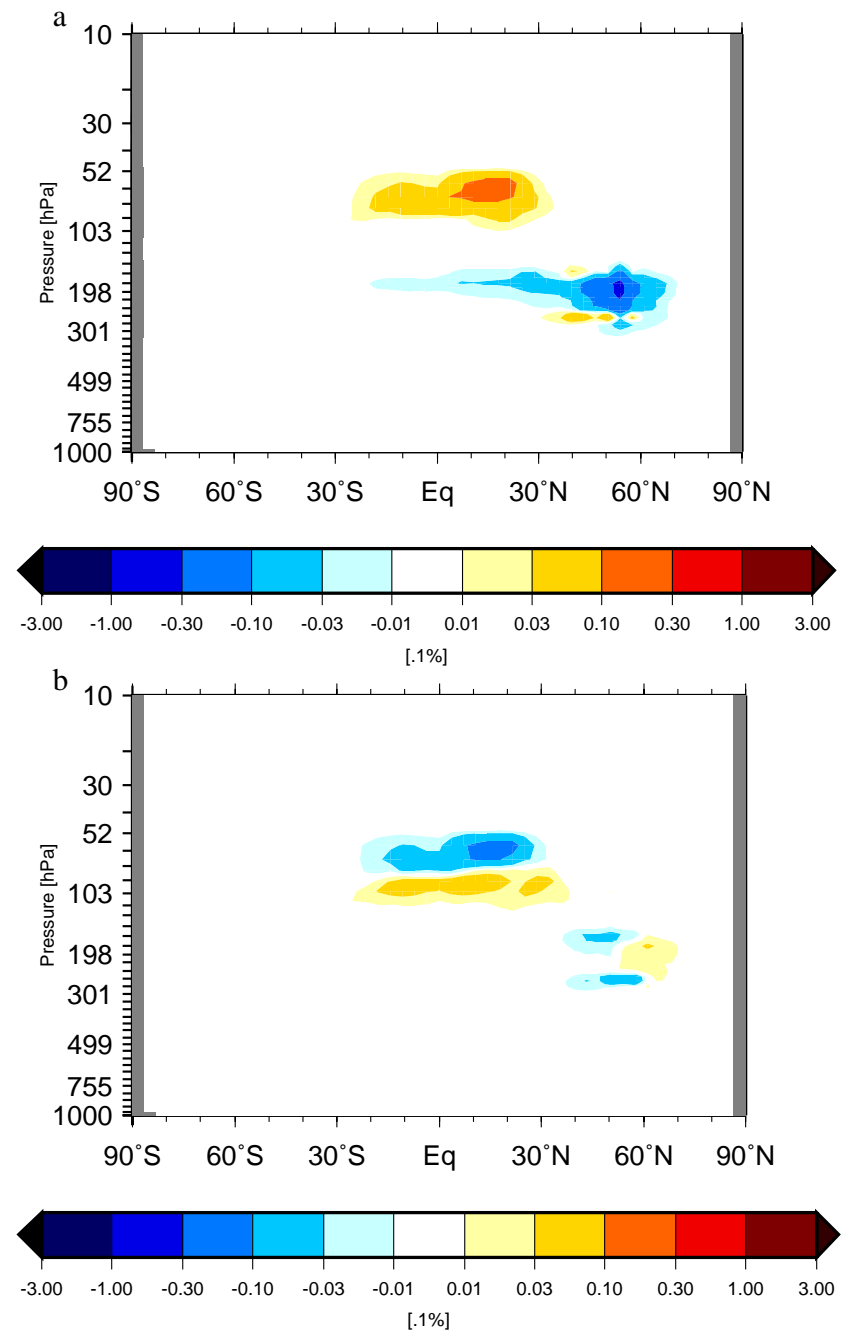

Fig. 6. Simulated change in contrail coverage (\%) induced by a substitution of subsonic aircraft by supersonic aircraft (S5 minus S4) (a) and effect of a lower cruising speed (P4 versus S5) (b).

Nitrogen oxides emitted by HSCTs experience the same transport characteristics as water vapour, which leads to differently simulated impacts in ozone perturbations among the models. To some extent, the maximum ozone perturbation line is parallel to the maximum water vapour perturbation, but shifted to higher altitudes. This is a consequence of the interaction of chemistry and transport. The $\mathrm{NO}_{\mathrm{x}}-$ destruction cycle of ozone has an increasing efficiency with height (chemistry) and the $\mathrm{NO}_{\mathrm{y}}$ changes are comparable to the $\mathrm{H}_{2} \mathrm{O}$ changes, i.e. varying among the models (transport). Furthermore, the ozone concentration is more dynamically controlled at lower altitudes and changes to a more chemically controlled regime at higher altitudes. Differences between the models occur at the Southern Hemisphere, where ozone changes from higher altitudes are effectively transported downwards. Since the OsloCTM2 model shows the maximum water vapour perturbation at the lowest altitude, the ozone impact on the Southern Hemisphere is the smallest among all models, leading to a larger inter-hemispheric contrast (Table 4). The SLIMCAT, E39/C and ULAQ models show larger tropical water vapour perturbations at $10 \mathrm{hPa}$ with around $250 \mathrm{ppbv}, 100 \mathrm{ppbv}$, and $100 \mathrm{ppbv}$, respectively (Fig. 3) than the OsloCTM2 model. Consequently also the $\mathrm{NO}_{\mathrm{y}}$ and $\mathrm{NO}_{\mathrm{x}}$ perturbations are larger in those models leading to a maximum in the ozone perturbation in the tropical region: All 3 models show a ratio of the $\mathrm{H}_{2} \mathrm{O}$ to ozone perturbation of 5:1. Hence absolute changes differ but not the ratio of the $\mathrm{NO}_{\mathrm{y}}$ to ozone perturbation. This indicates that chemistry shows a comparable response but transport differs significantly among the models.

The decrease of speed of the HSCT fleet (P4) reduces the loss of ozone by approximately $35 \%$, ranging between 5 and $60 \%$ (Table 4). The mean ozone mass is increasing considerably.

\subsection{Methane}

The change of ozone and water vapour in the stratosphere and troposphere leads also to a change of the tropospheric ozone and $\mathrm{OH}$ concentration. This reduces the methane lifetime by between $0.01 \%$ (ULAQ) and $0.44 \%$ (E39/C). Most likely two effects are leading to the simulated decrease in methane lifetime. The models E39/C and ULAQ simulate an increase in ozone in the troposphere, which directly leads to an increase in $\mathrm{OH}$. Further, a decrease in total ozone column increases the UV-flux into the troposphere where it increases the chemical activity (Taalas et al., 1997; Isaksen et al., 2005; Grewe, 2007). The models E39/C and OsloCTM2 simulate a stronger decrease in total ozone column than the ULAQ model, which most likely also leads to stronger $\mathrm{OH}$ increases, which is consistent with the calculated methane lifetime changes.

\subsection{Contrails}

The change in contrail coverage of a mixed fleet (S5) compared to the subsonic fleet (S4) is presented in Fig. 6 as simulated by E39. In the Northern Hemisphere upper troposphere / lower stratosphere region, contrail coverage is reduced, because of the substituted subsonic aircraft. Small increases are simulated at around $150 \mathrm{hPa}$ and $250 \mathrm{hPa}$, which are related to supersonic aircraft flying over land at subsonic speed, e.g. between $9 \mathrm{~km}$ and $13 \mathrm{~km}$, but at different altitudes than the replaced subsonic aircraft. At supersonic cruise altitude only the tropics are humid and cold enough to allow contrail formation. The global contrail coverage is reduced by only $1.6 \%$, i.e. from $0.3752 \%$ to $0.3692 \%$, because the tropical increase almost compensates the contrail reduction at higher latitudes. Although the difference is significant at a $99 \%$ level (t-test), the changes are so small that they can be regarded to be negligible. 
Table 5. Summary of aerosol mass changes and radiative forcing (global-annual averages) for base and sensitivity experiments (BC, $\left.\mathrm{SO}_{4}\right)$.

\begin{tabular}{|c|c|c|c|c|c|c|}
\hline \multirow[t]{2}{*}{ Scenario } & \multicolumn{2}{|c|}{$\Delta \mathrm{BC}$} & \multirow{2}{*}{$\begin{array}{l}\mathrm{RF} \\
\frac{\mathrm{mW}}{\mathrm{m}^{2}}\end{array}$} & \multicolumn{2}{|c|}{$\Delta \mathrm{SO}_{4}$} & \multirow{2}{*}{$\begin{array}{l}\mathrm{RF} \\
\frac{\mathrm{mW}}{\mathrm{m}^{2}}\end{array}$} \\
\hline & $10^{5} \mathrm{~kg}$ & $\%$ & & $10^{6} \mathrm{~kg}$ & $\%$ & \\
\hline S5-S4 (mixed) & 7.7 & - & 4.6 & 27 & - & -11.4 \\
\hline P2-S4 $\left(\mathrm{EINO}_{\mathrm{x}}\right)$ & 7.7 & 0 & 4.6 & 27 & 0 & -11.6 \\
\hline P3-S4 (size) & 18.9 & +145 & 11.0 & 55 & +104 & -23.3 \\
\hline P4-S4 (speed) & 3.1 & -60 & 1.7 & 13 & -52 & -5.6 \\
\hline P5-S4 (range) & 11.7 & +39 & 7.0 & 40 & +48 & -16.9 \\
\hline P6-S4 (height) & 0.5 & -94 & 0.4 & 9 & +67 & -3.9 \\
\hline
\end{tabular}

Flying at lower speed (P4) also induces compensating effects. Especially in the tropics, the contrail coverage is basically shifted in altitude. The global contrail coverage is reduced by $1.8 \%$, i.e. from $0.3752 \%$ to $0.3686 \%$, compared to the subsonic fleet (S4). Although the vertical and horizontal pattern of the contrail coverage changes significantly in the scenarios S4, S5 and P4, the global contrail coverage is only little affected (Stenke et al., 2007a).

\subsection{Particles}

The ULAQ model, which includes an aerosol module, has been used to calculate the differences in aerosol particle size and mass (black carbon and sulphate aerosols) produced by future supersonic aircraft. The effect of supersonic aircraft sulphur emission is to greatly increase the number of ultrafine particles; in addition, an enhanced accumulation mode is produced by the additional sulphur dioxide released on the large atmospheric scales, becoming available for sulphuric acid production after oxidation. The large increase in the ultrafine particle mode is expected to have a significant impact in the total particle surface area density available for heterogeneous chemical reactions, while the perturbation in the accumulation mode is important for the solar radiation scattering and climate forcing. It is important to note that aviation aerosols may also affect climate indirectly, via ozone changes produced by the enhanced heterogeneous chemistry (see Pitari et al., 2002b), which is not taken into account in this study.

The total atmospheric mass of black carbon and sulphate aerosols are increased by almost $8 \times 10^{5} \mathrm{~kg}$ and $27 \times 10^{6} \mathrm{~kg}$ (Table 5). The perturbation scenarios are in line with the results for water vapour perturbations. The perturbation of the global mean stratospheric water vapour by a mixed fleet (S5S4) is reduced by $57 \%$ when lowering the supersonic cruising speed (P4) in the ULAQ model. This value is close to respective changes in $\mathrm{BC}$ and $\mathrm{SO}_{4}$ perturbations of $-60 \%$ and $-52 \%$, respectively.

\section{Climate change}

Based on the concentration changes described above, we now investigate the consequences for climate change in terms of radiative forcing and near surface temperature changes, following the methodology described in Sects. 3.3 and 3.4 (see also Fig. 1).

\subsection{Radiative forcing}

Based on the CCM and CTM calculations for water vapour and ozone, the stratospheric adjusted radiative forcing has been calculated for the various cases. Table 6 summarizes all $\mathrm{RF}$ results for the base case, i.e. the replacement of the subsonic aircraft by supersonic aircraft (S5-S4). They are derived with a set of models for some species (water vapour, ozone, methane), for others (contrails, aerosols: black carbon and sulphate aerosols) with one model only. Since supersonic aircraft consume more fuel per passenger kilometer, the RF increase associated with $\mathrm{CO}_{2}$ amounts to around $3 \frac{\mathrm{mW}}{\mathrm{m}^{2}}$ in 2050.

Clearly, water vapour is the most important climate agent with respect to supersonic transport with values between 15 and $35 \frac{\mathrm{mW}}{\mathrm{m}^{2}}$ in 2050 and a mean value of $23 \frac{\mathrm{mW}}{\mathrm{m}^{2}}$. The variability can partly be explained by the variability in the differently simulated total water vapour increase: The OsloCTM2, ULAQ and SLIMCAT models show a similar response with $0.37 \pm 0.02 \mathrm{~mW} / \mathrm{m}^{2} / \mathrm{Tg}$, whereas the E39/C model shows $0.28 \mathrm{~mW} / \mathrm{m}^{2} / \mathrm{Tg}$. This lower value very likely results from the higher water vapour background in the E39/C model, leading to saturation effects (Forster et al., 2001).

For ozone the values range between -8.6 and $4.7 \frac{\mathrm{mW}}{\mathrm{m}^{2}}$. The differences are due to differences in the background ozone concentrations, perturbation pattern, and strength. E.g., for the E39/C model the ozone change is mainly confined to higher altitudes (Fig. 4), i.e. to a region where the ozone net RF changes its sign (Hansen et al., 1997), whereas the other models show also changes at lower stratospheric altitudes, where ozone changes are positively correlated with net RF.

The changes in the lifetime of tropospheric methane results in a mean change of the RF of $-1.59 \frac{\mathrm{mW}}{\mathrm{m}^{2}}\left(0.11 \frac{\mathrm{mW}}{\mathrm{m}^{2}}-\right.$ $3.33 \frac{\mathrm{mW}}{\mathrm{m}^{2}}$ ) and is therefore on a global scale for one model of the same order of magnitude like the RF perturbation caused by $\mathrm{CO}_{2}$.

The change in contrails occurrence tends to reduce the climate impact, since more supersonic air traffic is replacing subsonic air traffic at higher latitudes (leading to contrail avoidance) than at lower latitudes (leading to additional contrails). However, the changes are almost negligible.

The total RF ranges between 9 and $29 \frac{\mathrm{mW}}{\mathrm{m}^{2}}$ with a mean value of $22 \frac{\mathrm{mW}}{\mathrm{m}^{2}}$. The large range of uncertainty of a factor of three reflects the uncertainties in a number of processes included: stratospheric transport, chemistry and radiation.

Previous studies showed that the uncertainty in the calculation of the radiative forcing is less than $10 \%$ except for 
Table 6. Radiative forcing $\left(\frac{\mathrm{mW}}{\mathrm{m}^{2}}\right)$ of the perturbations from the replacement by supersonic aircraft (Scenario S5-S4) on the basis of various model results. Calculations are based on the E39 radiation code. Additionally, a calculation of the RF using the ULAQ radiation code and ULAQ perturbation pattern is used. The calculation of the totals includes the mean values for $\mathrm{CH}_{4}$ for the SLIMCAT model. Abbreviations: ctr: contrails; bc: Black carbon; sulph: sulphate aerosol; ACM = Atmosphere Chemistry Model; RF-Model, Model applied for radiative forcing calculations. ${ }^{*}$ Radiative forcing by $\mathrm{CO}_{2}$ is not calculated with a complex radiation code, but estimated via the $\mathrm{CO}_{2}$ concentration change (see text).

\begin{tabular}{|c|c|c|c|c|c|c|c|c|c|c|}
\hline $\mathrm{ACM}$ & RF-Model & $\mathrm{CO}_{2}^{*}$ & $\mathrm{H}_{2} \mathrm{O}$ & $\mathrm{O}_{3}$ & $\mathrm{CH}_{4}$ & Total & Ctr. & $\mathrm{BC}$ & Sulph. & Total \\
\hline $\mathrm{E} 39 / \mathrm{C}$ & E39 & 3.3 & 17.7 & 0.3 & -3.3 & 18.0 & -0.6 & & & 17.4 \\
\hline OsloCTM2 & E39 & 3.3 & 23.0 & -7.4 & -1.3 & 9.0 & & & & \\
\hline ULAQ & E39 & 3.3 & 15.8 & 4.7 & -0.1 & 23.3 & & & & \\
\hline SLIMCAT & E39 & 3.3 & 35.9 & -8.6 & $(-1.6)$ & 29.0 & & & & \\
\hline Mean & & 3.3 & 23.1 & -2.8 & -1.6 & 21.9 & & & & \\
\hline ULAQ & ULAQ & 3.3 & 33.0 & -3.8 & -0.1 & 32.4 & & 4.6 & -11.4 & 25.6 \\
\hline
\end{tabular}

Table 7. Climate sensitivity parameters and efficacy factors for various species and regions calculated with the E39-MLO model. Values marked with $(*)$ are taken from Ponater et al. (2006). $\mathrm{O}_{3}$-ls and $\mathrm{O}_{3}$-ut denote uniform ozone increase in the lower stratosphere and upper troposphere, respectively. $\mathrm{O}_{3}^{\text {subsonic }}$ and $\mathrm{H}_{2} \mathrm{O}^{\text {subsonic }}$ denote ozone change and water vapour change patter calculated with E39/C an E39, respectively.

\begin{tabular}{lccccccc}
\hline & $\mathrm{CO}_{2}$ & $\mathrm{CH}_{4}$ & $\mathrm{O}_{3}-\mathrm{ls}$ & $\mathrm{O}_{3}$-ut & $\mathrm{O}_{3}^{\text {subsonic }}$ & $\mathrm{H}_{2} \mathrm{O}^{\text {subsonic }}$ & contrails \\
\hline$\lambda\left[\mathrm{K} /\left(\mathrm{W} / \mathrm{m}^{2}\right)\right]$ & $0.73^{*}$ & $0.86^{*}$ & 1.31 & 0.55 & $0.88-1.15$ & $0.83^{*}$ & $0.43^{*}$ \\
Efficacy factor $\frac{\lambda}{\lambda \mathrm{CO}_{2}}$ & 1 & 1.18 & 1.80 & 0.75 & $1.20-1.56$ & 1.14 & 0.59 \\
\hline
\end{tabular}

water vapour (Forster et al., 2001) and therefore smaller than differences between the transport and chemical calculations. For water vapour, the ULAQ radiation scheme shows a factor of 2 higher values than the E39 model, employing the same water vapour perturbation and background field (Table 6). The results are consistent with previous findings (IPCC, 1999), which showed an uncertainty of a factor of two in the calculation of the water vapour related RF, with lower values derived with E39 model, compared to a narrow band model (Forster and Shine, 1997).

Supersonic aircraft will lead to enhanced particle mass concentration (black carbons and sulphate aerosols) and number concentration, especially in the ultra-fine and accumulation mode (see Sect. 4.6). Since only one model (ULAQ) simulated those changes, we consider the calculated impact as a sensitivity study, to prevent a too large dependency on model uncertainties. The calculation of the associated RF is performed with the ULAQ model. Table 6 and Fig. 7 summarize the results. The net direct aerosol effect on radiative forcing is negative and may be in the same order as the ozone related radiative forcing.

Figure 8 shows the changes in RF of the perturbation scenarios for constant total RPK (a) and constant supersonic RPK (b). The almost doubling of the fleet size approximately doubles the total RF caused by the replacement of sub- by su-

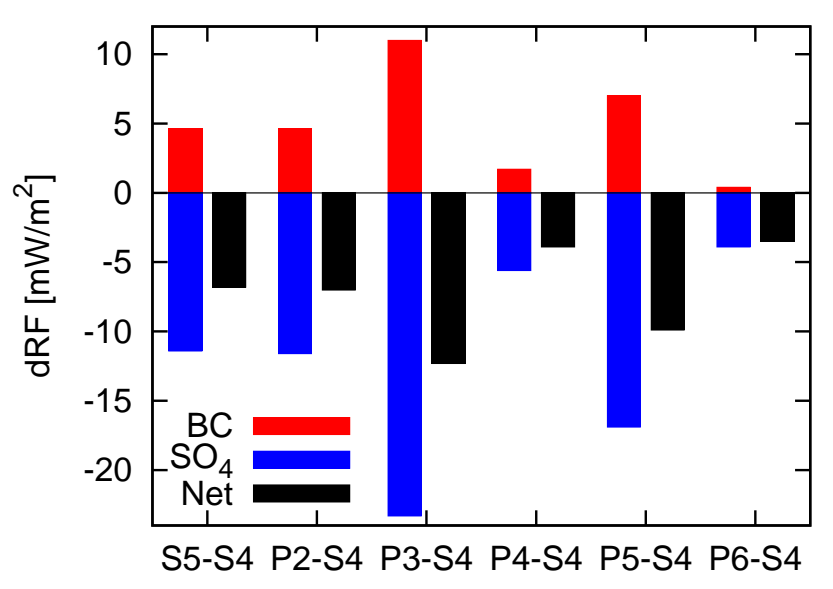

Fig. 7. Changes in BC, sulphate and net radiative forcing $\left(\frac{\mathrm{mW}}{\mathrm{m}^{2}}\right)$ calculated with perturbed scenarios including the aircraft perturbation on aerosol particles.

personic aircraft (P3). The total RF is mainly dominated by the water vapour effect, which scales linearly, since transport of water vapour is nearly a linear process in the stratosphere, except for sedimentation of ice particles. Note that transport of a species is linear in many cases although dynamics are 

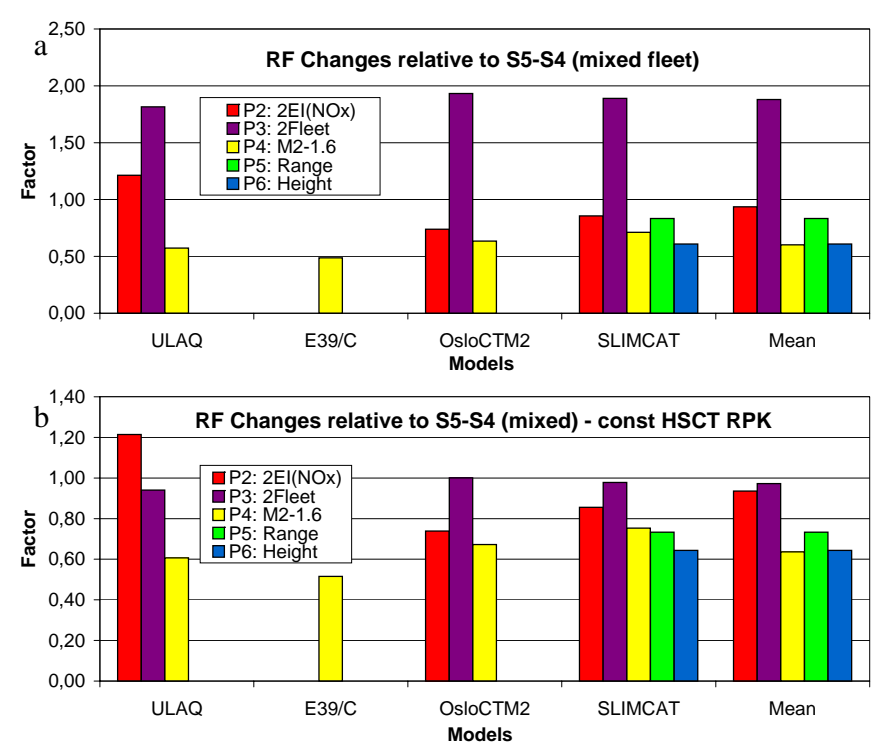

Fig. 8. Changes of the total RF (dimensionless) of the perturbation scenarios P2 to P6 (Px minus S4) relative to the base case (S5 minus S4) (a) and normalized to the HSCT RPK (b).

highly non-linear. An increased emission index of nitrogen oxides (P2) increases the ozone destruction, which reduces the RF between approximately 15\% (SLIMCAT) and 40\% (ULAQ). Other agents are mainly unaffected. The ozone induced RF is increased by a factor of 2.7 in the ULAQ model and by 1.8 in the two other models. Since the water vapour induced RF in the ULAQ model is smallest among the models (Table 6) and the ozone induced RF changes in the P2 scenario is largest, the $\mathrm{P} 2$ effect is maximized in the ULAQ model and on the other hand minimized in the SLIMCAT model.

Reducing the speed (P4) reduces the total RF by approximately $45 \%$, ranging from $30 \%$ (SLIMCAT) to 55\% (ULAQ). This is mainly caused by the reduction in fuel use of the supersonic fleet (33\%, Table 3) and the reduction of the lifetime of the water vapour perturbation (10\%, Table 3$)$. The simulations with an enhanced range and reduced height were performed with the SLIMCAT model, only. The RF is reduced in the scenario P5 (increased range) by $17 \%$, resulting from water vapour effects (10\%) and ozone effects (7\%). In the scenario P6 (reduced height) the total RF is reduced by $40 \%$, which mainly results from water vapour. However, the difference between the SLIMCAT model and the others in the scenario P4 is quite large. Moreover, the mean value (of all models) of the reduction factor of 0.55 for P4 (Fig. 8) is smaller than for P6 (0.61), but looking at the model, which was used for all simulations (i.e., SLIMCAT) the impact is reversed (P4: 0.71; P6: 0.61). Therefore, it cannot clearly be decided whether $\mathrm{P} 4$ or $\mathrm{P} 6$ has the higher reduction factor.

\subsection{Climate sensitivity}

In order to derive the global mean near surface temperature change associated with the supersonic HSCT, the RF has to be combined with the climate sensitivity of each individual climate agent (Eq. 3). As explained in Sect. 3, the model dependency of the efficacy is relatively small and it is sufficient to rely on one model. We applied the E39 model coupled to a mixed layer ocean, which has been used previously to identify climate sensitivity parameters relevant for aircraft perturbations (e.g., Ponater et al., 2006). Ponater et al. (2005), e.g., found a climate sensitivity of $0.73 \mathrm{~K} /\left(\mathrm{W} / \mathrm{m}^{2}\right)$ for $\mathrm{CO}_{2}$ and $0.43 \mathrm{~K} /\left(\mathrm{W} / \mathrm{m}^{2}\right)$ for line-shaped contrails, i.e. a contrail efficacy of 0.59 . Further climate sensitivity parameters are given in Tab. 7 for methane, ozone in the lower stratosphere $\left(\mathrm{O}_{3}\right.$-ls $)$ and upper troposphere $\left(\mathrm{O}_{3}\right.$-ut $)$ and for a set of subsonic aircraft perturbations. The idealized scenarios $\mathrm{O}_{3}$-ls and $\mathrm{O}_{3}$-ut follow the experimental design of Stuber et al. (2001, 2005). Their efficacy factors derived with the 19 layer version of ECHAM4 of 1.82 and 0.72 are almost identical to our values of 1.80 and 0.75 (E39; 39 layer version of ECHAM4) for $\mathrm{O}_{3}$-ls and $\mathrm{O}_{3}$-ut, respectively. The subsonic aircraft perturbations are taken from previous simulations (Grewe et al., 2002). Clearly the ozone impact is more dominated by the contributions from the lower stratosphere. For the near temperature change calculations we adopt the $\mathrm{O}_{3}$-ls climate sensitivity parameter for stratospheric perturbations and additionally take a $20 \%$ uncertainty into account. For water vapour changes in the stratosphere, we assume an efficacy factor of 1 and take also into account a $20 \%$ uncertainty (see section below), since there are no sufficient indications that stratospheric water vapour has a climate sensitivity parameter significantly different from $\mathrm{CO}_{2}$

\subsection{Climate impact}

In the previous sections we prepared all necessary input to estimate the climate impact of HSCT. Clearly, the water vapour impact dominates and leads to an increase of $21 \mathrm{mK}$ by the year 2100. Note that although emissions are kept constant during the years 2050 to 2100 , the temperature is still increasing due to the atmospheric response times. Ozone is the second-strongest contributor to climate change, with a reduction in the temperature increase of $3.0 \mathrm{mK}$. The uncertainty with respect to atmospheric lifetime of the water vapour and ozone perturbations is negligible (not shown).

However, other parameters do also introduce nonnegligible uncertainties. Taking into account the minimum and maximum values of the calculated RF (Table 6) and a $20 \%$ uncertainty for the climate sensitivity introduces a much larger uncertainty. The water vapour impact on temperature changes ranges between 13 and $45 \frac{\mathrm{mW}}{\mathrm{m}^{2}}$ and for ozone between -13 and $4.5 \frac{\mathrm{mW}}{\mathrm{m}^{2}}$. This implies that the order of the temperature change in the extremest case may be in the same range for water vapour and ozone (Fig. 9b). 
Comparing all scenarios (Fig. 9c) with a scaling by the HSCT traffic demand (RPK), it is clear that the climate impact can be reduced by $\approx 40 \%$ using the options $\mathrm{P} 4$ (speed), P5 (range), and P6 (height).

So far, our discussion has concentrated on the climate change aspect, only. Other aspects like the change in the ozone layer, which impacts ultra-violet radiation are discussed in the following section.

\section{Synthesis and optimization}

In Sects. 4 and 5 we have discussed how, according to the various model results, the emissions from the SCENIC HSCT scenarios affect climate and the ozone layer. Figure 10 shows a combined metric: the 2100 changes of near surface temperature with respect to a base case HSCT fleet (filled bars) and the changes in the ozone layer (dashed bars) for constant RPK (blue) and normalized to a constant HSCT RPK (red). The best option would clearly be achieved, when both bars are minimal. Looking at constant RPK the P4 (reduced speed) and the P6 (reduced cruise altitude) option show a minimum impact. P5 (range increase) also has a smaller impact for the combined effect (temperature and ozone layer) than the base case. However, the increase in range leads to more flights being routed to South East Asia, which in turn leads to more emissions in the tropical tropopause layer and therefore a more intense transport of emitted $\mathrm{NO}_{\mathrm{x}}$ into the stratosphere, so that ozone destruction is enhanced in the scenario P5 compared to the base case. The error bars indicate the minimum and maximum values, which can be obtained including all uncertainties discussed in the previous sections, like model dependent chemical perturbation, RF calculations, and climate sensitivity. Taking this uncertainty into account the scenarios P4 and P6 both minimize the environmental impact. Both metrics can be combined by calculating their product (green bars), which better visualizes the results.

The uncertainty regarding the scenario $\mathrm{P} 2$ is largest because the increase in the $\mathrm{EI}\left(\mathrm{NO}_{\mathrm{x}}\right)$ leads to ozone destruction and near surface temperature decrease. This may compensate the water vapour induced temperature changes, when assuming the lowest simulated water vapour RF and climate sensitivity, which is an extreme case.

The lower the supersonic cruise altitude or the lower the cruising speed, the less the gain in time compared to subsonic flights. Therefore such a scenario is less economical viable. However, increasing range may increase the viability with less environmental impacts compared to an increase in speed.

Aerosol effects were not included for this optimization considerations, since we expect a model dependency according to different simulated transport characteristics (cf. Table 3) and aerosol physics. In general, we tried to account for uncertainties by applying a set of models, which was not possible for aerosols. However, since the total aerosol RF

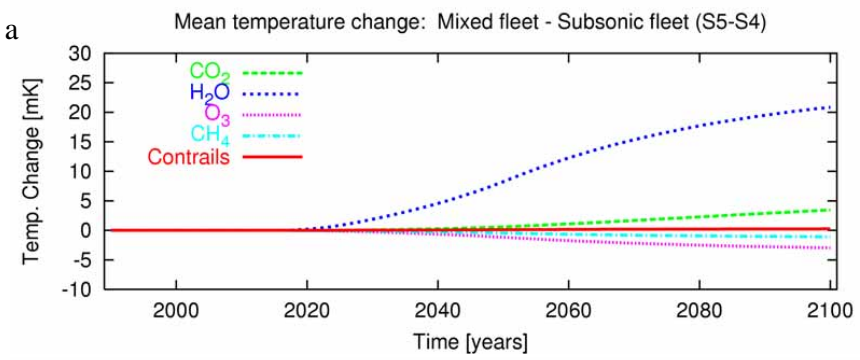

b $\quad \mathrm{Min}_{2} \mathrm{O}$
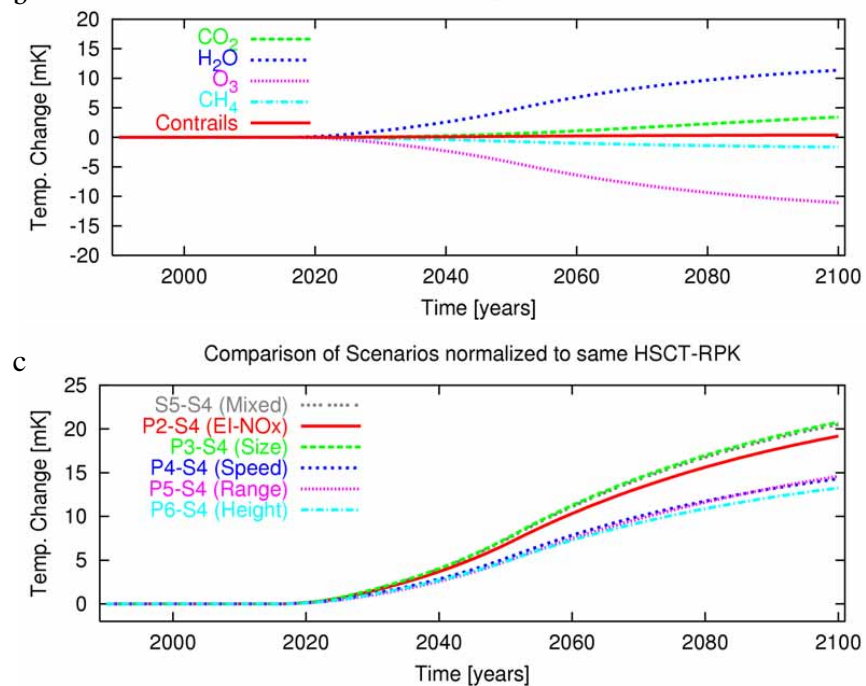

Fig. 9. Temporal development of the near surface temperature change $[\mathrm{mK}]$ induced by a partial replacement of the subsonic aircraft (S5 minus S4). (a) Attribution to the climate agents $\mathrm{CO}_{2}$ (green), $\mathrm{H}_{2} \mathrm{O}$ (blue), $\mathrm{O}_{3}$ (magenta), $\mathrm{CH}_{4}$ (light blue), and contrails (red). (b) Minimum water vapour effect, when choosing parameters in the extremes of the uncertainty range. (c) Total change for the scenarios $\mathrm{S} 5, \mathrm{P} 2, \ldots, \mathrm{P} 6$ with respect to $\mathrm{S} 4$ (subsonic fleet).

changes for the scenarios P2 to P6 (Fig. 7) are similar to the $\mathrm{RF}$ changes due to water vapour, though smaller, it can be expected that the uncertainty related to the aerosol effects are of minor importance and do not significantly alter our findings.

\section{Discussion of uncertainties}

In our analysis a number of uncertainties are taken into account, either by including a certain range, e.g. $\pm 20 \%$ for water vapour and ozone climate sensitivity parameter or an uncertainty range is taken from the different modelling results (RF, lifetimes, ...). Those uncertainties were used to determine a temperature range. Although we took into account a large number of uncertainties, there are still a couple of processes, which we could not include in more detail. Among those are climate-chemistry feedbacks and some aspects of the calculation of the radiative forcing. 


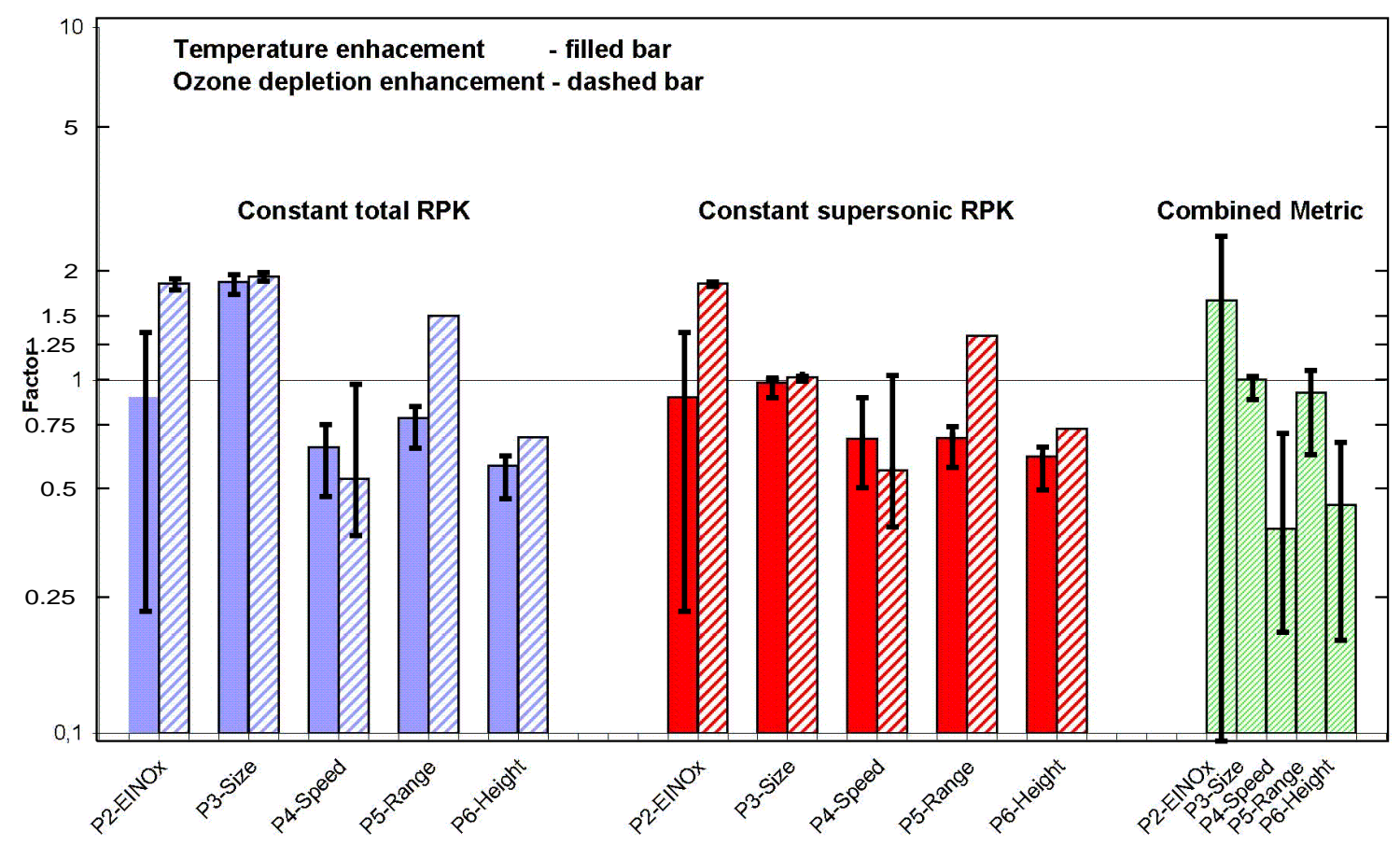

Fig. 10. Changes in near surface temperature for the year 2100 (solid bars) and for ozone (dashed bars) for constant RPK of the total fleet (blue) and constant HSCT RPK (red). The product of both factors is added (green) for constant HSCT RPK. For each bar an uncertainty range is given, which represents minimum and maximum values. No bars are added when only one model has calculated chemical perturbations. In those cases the same uncertainty range has been assumed as for P4 for the calculation of the uncertainty of the product. The base case perturbation (S5 minus S4), i.e. the mixed fleet minus subsonic fleet, is taken as reference $(=1)$.

The main climate-chemistry feedbacks are induced by changes in ozone and water vapour (S5-S4), which cause changes in the vertical profile of the heating rates and hence the circulation. Changes in heating rates were calculated for all models, changes in the circulation and impact on chemistry only for E39/C. Water vapour changes lead to a quite consistent change in heating rates among all models. A decrease in stratospheric and increase in upper tropospheric heating rates is found in all models, dominated by its longwave contribution. The impact of ozone changes on the heating rates is less consistent, since the ozone changes themselfes are less consistent among the models. A decrease of the net heating rates is found in the SLIMCAT and OsloCTM2 models, peaking at around $200 \mathrm{hPa}$. In the ULAQ model the ozone increase at lower stratospheric levels leads to an increase of the heating rates, whereas in E39/C the effects are balanced.

The described changes in heating rates have an impact on circulation and climate. Within the SCENIC project we performed feed-back calculations with E39/C. These simulations mainly show a statistical significant increase in the stratospheric water vapour concentration of $100 \mathrm{ppbv}$ on both hemispheres, which is roughly one third of the direct increase of water vapour due to the substitution of subsonic aircraft by supersonics. The increase is accompanied by an increase in the cold point temperature and an increase in the water vapour entry level, which were, however, statistically not significant. Therefore, the mechanism, how climate change, induced by the substitution of subsonic by supersonic aircraft, leads to an increase in stratospheric water vapour in the E39/C model remains unclear. The feedback induced water vapour changes are hence regarded to be too uncertain to be included in our analysis.

Another uncertainty refers to the impact of a seasonal cycle in the perturbation field on changes in radiation and hence radiative forcing. Note that the calculation of concentration changes and RF takes into account a seasonal cycle. The seasonal cycle in the water vapour perturbation is calculated similar among the models with maximum values in $\mathrm{Au}-$ gust/September. However, their amplitudes are quite different, with largest values for E39/C (20\%). The impact on water vapour induced radiation changes is regarded to be small since it may only affect the shortwave contribution, which is of minor importance for water vapour.

\section{Conclusions}

In this study we have suggested a way how to evaluate options for aircraft in terms of global environmental impact (chemical composition and climate). The methodology re- 
sults in a combination of the near surface temperature change and a change of the stratospheric ozone depletion relative to a base case. The base case has been a mixed fleet of subsonic aircraft and 501 supersonic aircraft with a cruise speed of Mach 2 and a capacity of 250 passengers. For the perturbation scenarios supersonic aircraft configurations are taken into account with an increased emission index for $\mathrm{NO}_{2}$ during supersonic cruise (P2), a doubled fleet size (P3), or which are optimized with respect to a lower cruising speed (P4), an extended range (P5), and a reduced cruise altitude (P6).

The applied assessment approach utilizes a number of component models which are stepwise linked (Fig. 1). In a first step, a transient emission scenario for total fuel use is developed based on the SCENIC emission databases for 2025 and 2050 and on the TRADEOFF database for the present. In a second step, concentration changes are calculated for ozone, water vapour and methane employing 4 global atmosphere-chemistry models for the time slice 2050 . Contrail coverage changes are calculated based on the E39/C model. The stratospheric adjusted radiative forcing is then calculated by applying a general circulation model employing the output of the atmosphere-chemistry model simulations. Various climate sensitivity parameters are calculated based on a general circulation model coupled to a mixed layer ocean. Utilizing a linear response model (AirClim), the radiative forcings and the climate sensitivity parameters are converted into an estimate of the near surface temperature change, allowing for different response time-scales of the chemistry-atmosphere-ocean system. All steps include some uncertainties, which are either determined through the spread of model results, or taken from the literature. These uncertainties are determined for each individual component and then combined to give an overall uncertainty for the combined optimization metric.

In principle this approach has already been used in IPCC (1999). However, they concentrated on RF and ozone column changes and did not try to optimize the combined effect.

The results clearly confirm previous findings (IPCC, 1999): stratospheric water vapour emissions are by far the most important contributor to climate change with respect to a supersonic fleet. Only considering the extremes in the uncertainty range, stratospheric ozone changes may become as important as stratospheric water vapour changes. The total radiative forcing by supersonic aircraft amounts to $22 \frac{\mathrm{mW}}{\mathrm{m}^{2}}$ in 2050 , with a rather large range of uncertainty of 9 to $29 \frac{\mathrm{mW}}{\mathrm{m}^{2}}$, depending on the modelled chemical perturbations. Previous estimates, e.g. IPCC (1999), are in general difficult to compare, because the assumptions for the supersonic part of the mixed fleet, in terms of cruise altitude, routing and traffic demand differ significantly. IPCC (1999) gives an estimate of $82 \frac{\mathrm{mW}}{\mathrm{m}^{2}}$ induced by a replacement of 1000 aircraft by 2050 with a fuel consumption of $140 \mathrm{Tg}$ and a cruise speed of Mach 2.0 to 2.4, i.e. cruise altitude $18-20 \mathrm{~km}$. They estimated a range of uncertainty of $-25 \frac{\mathrm{mW}}{\mathrm{m}^{2}}$ to $300 \frac{\mathrm{mW}}{\mathrm{m}^{2}}$. In order to compare these values with our findings the different fuel usage and flight level has to be taken into account. By normalizing this value to the same fuel usage $(60 \mathrm{Tg}$; Table 3$)$ and allowing a reduction of $40 \%$ caused by the differences in flight altitude (1.5 km difference between S5 and HSCT1000 from IPCC (1999), as well as between S5 and P4) this can be scaled to a value of $21 \frac{\mathrm{mW}}{\mathrm{m}^{2}}$ and a range of $-6 \frac{\mathrm{mW}}{\mathrm{m}^{2}}$ to $77 \frac{\mathrm{mW}}{\mathrm{m}^{2}}$, leading to comparable results in this respect.

IPCC (1999) presented a best estimate for the total radiative forcing from subsonic air traffic of $190 \frac{\mathrm{mW}}{\mathrm{m}^{2}}$ in 2050 . Grewe and Stenke (2007) calculated roughly $200 \frac{\mathrm{mW}}{\mathrm{m}^{2}}$ for 2050 and $190 \mathrm{mK}$ for 2100 , though for different air traffic data (TRADEOFF, SCENIC) than IPCC, but consistent with the present study. The replacement of subsonic aircraft by supersonics (S5-S4) thus leads to an amplification of air traffic induced climate impact in the order of $10 \%$ with respect to RF in $2050\left(22 \frac{\mathrm{mW}}{\mathrm{m}^{2}}\right)$ and temperature change in 2100 $(21 \mathrm{mK})$.

The total anthropogenic temperature increase is estimated to be the range of $1.4 \mathrm{~K}$ to $5.4 \mathrm{~K}$ (IPCC, 2001), recently revised to $1.1 \mathrm{~K}$ to $6.4 \mathrm{~K}$ (IPCC, 2007). The underlying assumptions on economical growth and technological progress differ from the assumptions made in the present paper. Therefore direct comparison of numbers is not meaningful. However, the order of contribution of subsonic air traffic and the substitution by supersonics to the total expected anthropogenic temperature increase can be estimated. It is in the order of $10 \%$ (range $3-20 \%$ ) and $1 \%$ (range $0.3 \%$ to $2 \%$ ), respectively. Note that these numbers also depend on the assumptions for the overall growth of air traffic.

A direct quantitative intercomparison of supersonic and subsonic aircraft would be premature. Although climate impact metrics for subsonic air traffic (Sausen et al., 2005) and supersonic air traffic exists, their characteristics in terms of temporal development of fuel consumption, i.e. $\mathrm{CO}_{2}$ accumulation effects, and fleet design lack the consistency to be meaningfully intercompared. A direct intercomparison is given in Grewe and Stenke (2007): They estimated a fivetimes larger climate impact of a supersonic aircraft of the regared size compared to a subsonic counterpart.

The investigation of the various options shows that the largest reduction of an environmental impact of around 60\% can be achieved by reducing the speed or height to Mach 1.6 or by $1.5 \mathrm{~km}$, respectively. These scenarios are characterized by a lower fuel consumption of the HSCT fleet, leading to a lower water vapour perturbation. Additionally, the lower flight altitude leads to a reduced residence time of the water vapour perturbation by $10 \%$. Both factors reduce the radiative forcing and the climate change and also lead to reduced ozone depletion.

Acknowledgements. This study has been supported by the European Commission through the SCENIC project under the 5th Framework Programme and through the Integrated Project HISAC under the 6th Framework Programme. 
Edited by: W. Collins

\section{References}

Appleman, H.: The formation of exhaust contrails by jet aircraft, Bull. Americ. Meteorol. Soc., 43, 14-20, 1953.

Cess, R., Potter, G., Blanchet, J., Boer, G., Ghan, S., Kiehl, J., LeTreut, H., Li, Z.-X., Liang, X.-Z., Mitchell, J., Morcrette, J.J., Randall, D., Riches, M., Roeckner, E., Schlese, U., Slingo, A., Taylor, K., Washington, W., Wetherald, R., and Yaga, I.: Interpretation of cloud-climate feedback as produced by 14 atmospheric general circulation models, Science, 245, 513-516, 1989.

Chipperfield, M. P., Santee, M. L., Froidevaux, L., Manney, G. L., Read, W. G., and Waters, J. W., Roche, A. E., and Russell, J. M.: Analysis of UARS data in the southern polar vortex in September 1992 using a chemical transport model, J. Geophys. Res., 1001, 18 861-18 882, 1996.

Chipperfield, M. P.: Multiannual simulations with a threedimensional chemical transport model, J. Geophys. Res., 104, 1781-1806, 1999.

Crutzen, P.: Ozone production rates in an oxygen-hydrogennitrogen oxide atmosphere, J. Geophys. Res., 76, 7311-7327, 1971.

Fichter, C., Marquart, S., Sausen, R., and Lee, D. S.: The impact of cruise altitude on contrails and related radiative forcing, Meteorologische Zeitschrift, 14, 563-572, doi:10.1127/0941-2948/ 2005/0048, 2005.

Forster, P. and Shine, K.: Radiative forcing and temperature trends from stratospheric ozone changes, J. Geophys. Res., 106, 10 841-10 855, 1997.

Forster, P., Ponater, M., and Zhong, W.-Y.: Testing Broadband Radiation Schemes for their Ability to Calculate the Radiative Forcing and Temperature Response to Stratospheric Water Vapour and Ozone Changes, Meteorol. Z., 10, 387-393, 2001.

Fuglestvedt, J., Berntsen, T., Godal, O., Sausen, R., Shine, K., and Skodvin, T.: Metrics of climate change: Assessing radiative forcing and emission indices, Clim. Change, 58, 267-331, 2003.

Grewe, V.: Impact of climate variability on tropospheric ozone, Sci. Tot. Environm., 374, 167-181, doi:10.1016/j.scitotenv.2007.01.032, 2007.

Grewe, V. and Stenke, A.: A strategy for climate evaluation of aircraft technology: An efficient climate impact assessment tool - AirClim, Atmos. Chem. Physc. Discuss., 7, 12 185-12 229, 2007.

Grewe, V., Dameris, M., Fichter, C., and Sausen, R.: Impact of aircraft $\mathrm{NO}_{\mathrm{x}}$ emissions. Part 1: Interactively coupled climatechemistry simulations and sensitivities to climate-chemistry feedback, lightning and model resolution, Meteorol. Z., 3, 177186, 2002.

Hall, T. and Plumb, R.: Age as a diagnostic for stratospheric transport, J. Geophys. Res., 99, 1059-1070, 1994.

Hansen, J., Sato, M., and Ruedy, R.: Radiative forcing and climate response, J. Geophys. Res., 102, 6831-6864, 1997.

Hansen, J., Sato, M., Ruedy, R., Nazarenko, L., Lacis, A., Schmidt, G., Russell, G., Aleinov, I., Bauer, M., Bauer, S., Bell, N., Cairns, B., Canuto, V., Chandler, M., Cheng, Y., DelGenio, A., Faluvegi, G., Fleming, E., Friend, A., Hall, T., Jackman, C., Kelley, M., Kiang, N., Koch, D., Lean, J., Lerner, J., Lo, K., Menon, S.,
Miller, R., Minnis, O., Novakov, T., Oinas, V., Perlwitz, J., Perlwitz, J., Rind, D., Romanou, A., Shindell, D., Stone, P., Sun, S., Tausnev, N., Tresher, D., Wielicki, B., Wong, T., and Zhang, S.: Efficacy of climate forcings, J. Geophys. Res., 110, D18104, doi:10.1029/2005JD005776, 2005.

Hein, R., Damaris, M., Schnadt, C., Land, C., Grewe, V., Kóhler, I., Ponater, M., Sausen, R., Steil, B., Landgraf, J., and Brúhl, C.: Results of an interactively coupled atmospheric chemistry-general circulation model: Comparison with observations, Ann. Geophys., 19, 435-457, 2001.

Holton, J., Haynes, P., McIntyre, M., Douglass, A., Rood, R., and Pfister, L.: Stratosphere-troposphere exchange, Rev. Geophys., 33, 403-439, 1995.

IPCC: Climate Change 1994. The radiative forcing of climate change and an evaluation of the IPCC IS92 emission scenarios., Intergovernmental Panel on Climate Change, Cambridge University Press, New York, NY, USA, 1995.

IPCC: Special report on aviation and the global atmosphere, edited by: Penner, J. E., Lister, D. H., Griggs, D. J., Dokken, D. J., and McFarland, M., Intergovernmental Panel on Climate Change, Cambridge University Press, New York, NY, USA, 1999.

IPCC: Climate Change 2001 - The scientific basis. Contributions of working group I to the Third Assessment Report of the Intergovernmental Panel of Climate Change (IPCC), Intergovernmental Panel on Climate Change, Cambridge University Press, New York, NY, USA, 2001.

IPCC: Climate Change 2007 - The Physical Science Basis Contribution of Working Group I to the Fourth Assessment Report of the IPCC, Intergovernmental Panel on Climate Change, Cambridge University Press, New York, NY, USA, 2007.

Isaksen, I., Zerefos, C., Kourtidis, K., Meleti, C., Dalsøren, S. B., Sundet, J. K., Grini, A., Zanis, P., and Balis, D.: Tropospheric ozone changes at unpolluted and semipolluted regions induced by stratospheric ozone changes, J. Geophys. Res., 110, D02302, doi:10.1029/2004JD004618, 2005.

Johnson, C. and Derwent, R.: Relative radiative forcing consequences of global emissions of hydrocarbons, carbon monoxide and $\mathrm{NO}_{\mathrm{x}}$ from human activities estimated with a zonallyaveraged two dimensional model, Clim. Change, 34, 439-462, 1996.

Johnston, H.: Reduction of stratospheric ozone by nitrogen oxide catalysts from supersonic transport exhaust, Science, 173, 517522, 1971.

Joshi, M., Shine, K., Ponater, M., Stuber, N., Sausen, R., and Li, L.: A comparison of climate response to different radiative forcings in three general circulation models: towards an improved metric of climate change, Climate Dyn., 20, 843-854, 2003.

Land, C., Ponater, M., Sausen, R., and Roeckner, E.: The ECHAM4.L39(DLR) atmosphere GCM, Technical description and climatology, DLR-Forschungsbericht, 1991-31, 45 pp., ISSN 1434-8454, Deutsches Zentrum für Luft- und Raumfahrt, Köln, Germany, 1999.

Manabe, S. and Wetherald, R.: The effects of doubling the $\mathrm{CO}_{2}$ concentration on the climate of a general circulation model, J. Atmos. Sci., 32, 3-15, 1975.

Marquart, S. and Mayer, B.: Towards a reliable GCM estimation of contrail radiative forcing, Geophys. Res. Lett., 29, 1179, doi:10.1029/2001GL014075, 2002.

Marquart, S., Ponater, M., Mager, F., and Sausen, R.: Future de- 
velopment of contrail cover, optical depth and radiative forcing: Impacts of increasing air traffic and climate change, J. Climate, 16, 2890-2904, 2003.

Meyer, R., Büll, R., Leiter, C., Mannstein, H., Pechtl, S., Oki, T., and Wendling, P.: Contrail observations over Southern and Eastern Asia in NOAA/AVHRR data and intercomparison to contrail simulations in a GCM, Int. J. Remote Sens., 28, 2049-2069, doi:10.1080/01431160600641707, 2007.

Pitari, G., Mancini, E., and Bregman, A.: Climate forcing of subsonic aviation: Impact of sulfate particles via heterogeneous chemistry, Geophys. Res. Lett., 29, 14-1-14-4, 2002.

Pitari, G., Mancini, E., Rizi, V., and Shindell, D. T.: Impact of future climate and emission changes on stratospheric aerosols and ozone, J. Atmos. Sci., 59, 414-440, 2002a.

Ponater, M., Marquart, S., and Sausen, R.: Contrails in a comprehensive global climate model: Parameterisation and radiative forcing results, J. Geophys. Res., 107, 4164, doi:10.1029/2001JD000429, 2002.

Ponater, M., Marquart, S., Sausen, R., and Schumann, U.: On contrail climate sensitivity, Geophys. Res. Lett., 32, L10706, doi:10.1029/2005GL022580, 2005.

Ponater, M., Pechtl, S., Sausen, R., Schumann, U., and Hüttig, G.: Potential of the cryoplane technology to reduce aircraft climate impact: A state-of-the-art assessment, Atmos. Environm., 40, 6928-6944, doi:10.1016/j.atmosenv.2006.06.036, 2006.

Prather, M.: Numerical advection by conservation of second-order moments, J. Geophys. Res., 91, 6671-6681, 1986.

Sausen, R. and Schumann, U.: Estimates of the climate response to aircraft $\mathrm{CO}_{2}$ and $\mathrm{NO}_{\mathrm{x}}$ emissions scenarios, Clim. Change, 44, 25-58, 2000.
Sausen, R., Isaksen, I., Grewe, V., Hauglustaine, D., Lee, D. S., Myhre, G., Köhler, M. O., Pitari, G., Schumann, U., Stordal, F., and Zerefos, C.: Aviation Radiative Forcing in 2000: An Update on IPCC (1999), Meteorol. Z., 14, 555-561, 2005.

Schmidt, E.: Die Entstehung von Eisnebel aus den Auspuffgasen von Flugmotoren, Schriften der deutschen Akademie der Luftfahrtforschung, 44, 1-15, 1941.

Søvde, O., Gauss, M., Isaksen, I., Pitari, G., and Marizy, C.: Aircraft pollution - a futuristic view, Atmos. Chem. Physc., 7, 36213632, 2007.

Stenke, A., Grewe, V., and Pechtl, S.: Do supersonics avoid contrails?, Atmos. Chem. Phys. Discuss., 7, 12 927-12 958, 2007a.

Stuber, N., Sausen, R., and Ponater, M.: Stratosphere adjusted radiative forcing calculations in a comprehensive climate model, Theor. Appl. Climatol., 68, 125-135, 2001.

Stuber, N., Ponater, M., and Sausen, R.: Why radiative forcing might fail as a predictor of climate change, Clim. Dyn., 24, 497510, doi:10.1007/s00382-004-0497-7, 2005.

Sundet, J. K.: Model Studies with a 3-D Global CTM using ECMWF data, Dept. of Geophysics, University of Oslo, Norway, 1997.

Svensson, F., Hasselrot, A., and Moldanova, J.: Reduced environmental impact by lowered cruise altitude for liquid hydrogenfuelled aircraft, Aerosp. Sci. Technol., 8, 307-320, 2004.

Taalas, P., Damski, J., Kyrö, E., Ginzburg, M., and Talamoni, G.: Effect of stratospheric ozone variations on UV radiation and on tropospheric ozone at high latitudes, J. Geophys. Res., 102, 1533-1540, 1997.

Wetherald, R. and Manabe, S.: The effects of changing the solar constant on the climate of a general circulation model, J. Atmos. Sci., 32, 2044-2059, 1975. 